\title{
Venous thromboembolism prophylaxis in cancer patients - guidelines focus on surgical patients
}

\section{Tomasz Urbanek}

Department of General Surgery, Vascular Surgery, Angiology and Phlebology, Medical University of Silesia, Katowice, Poland Potential conflict of interest: yes

Educative lectures: Bayer, Boehringer Ingelheim, Sanofi, Aspen, Pfizer Advisory Board Member: Sanofi, Aspen

\section{Zbigniew Krasiński}

Department of General and Vascular Surgery, University of Medical Science, Poznan, Poland

Potential conflict of interest: yes

Educative lectures: Bayer, Boehringer Ingelheim, Sanofi, Aspen, Pfizer Advisory Board Member: Sanofi

\section{Maciej Kostrubiec}

Department of Internal Medicine and Cardiology with The Center of Diagnostics and Treatment of Venous Thromboembolic Disease, Medical University of Warsaw, Poland

Potential conflict of interest: no

\section{Wojciech Sydor}

${ }^{2 n d}$ Department of Internal Medicine, Jagiellonian University Medical College, Cracow, Poland

Potential conflict of interes: yes

Educative lectures: Bayer, Boehringer Ingelheim, Sanofi, B. Braun, UCB Pharma, Baxter, Medycyna Praktyczna

\section{Piotr Wysocki}

Department of Oncology, Jagiellonian University, Medical College, Cracow, Poland

Potential conflict of interest: yes

Advisory Board Member: Sanofi, Aspen

\section{Artur Antoniewicz}

Department of Urology, Specialist Hospital Miedzylesie, Poland Potential conflict of interest: no

\section{Beata Begier-Krasińska}

Department of Hypertensiology, Angiology and Internal Medicine, University of Medical Science, Poznan, Poland

Potential conflict of interest: no

\section{Wojciech Dyszkiewicz}

Department of Thoracic Surgery, University of Medical Sciences,

Poznan, Poland

Potential conflict of interest: no

\section{Jan Kulig}

Department of General Surgery, Jagiellonian University Medical College, Cracow, Poland

Potential conflict of interest: no

\section{Piotr Kadziński}

Department of Neurosurgery, Medical University of Silesia, Katowice,

Poland

Potential conflict of interest: no

\section{Janina Markowska}

Department of Gynecological Oncology, Clinical Hospital, Poznan, Poland

Potential conflict of interest: no

\section{Rodryg Ramlau}

Department of Oncology, University of Medical Sciences, Poznan, Poland

Potential conflict of interest: no

\section{Piotr Rutkowski}

Maria Sklodowska-Curie Memorial Cancer, Center and Institute of Oncology, Department of Soft Tissue/Osteosarcoma and Melanoma, Warsaw, Poland

Potential conflict of interest: yes

Educative lectures: Sanofi

\section{Stefan Sajdak}

Department of Surgical Gynaecology, University of Medical Sciences, Poznan, Poland

Potential conflict of interest: no

\section{Damian Ziaja}

Department of General Surgery, Vascular Surgery, Angiology and Phlebology, Medical University of Silesia, Katowice, Poland Potential conflict of interest: yes Advisory Board Member: Sanofi

\section{Krzysztof Ziaja}

Department of General Surgery, Vascular Surgery, Angiology and Phlebology, Medical University of Silesia, Katowice, Poland Potential conflict of interest: yes Advisory Board Member: Sanofi

The document content was approved by the following representatives of the Scientific Societes:

Tomasz Zubilewicz - President of Polish Society of Phlebology

Piotr Szopiński - President of Polish Society for Vascular Surgery

Grzegorz Oszkinis - Past-President of Polish Society for Vascular Surgery

Rafał Niżankowski - President of Polish Society of Angiology (Approve with the statement: "I accept the guideline document with the strong belief concerning the necessity of the carefull application of antithrombotic prophylaxis in cancer patients, especially the necessity of the combination of heparin prophylaxis and the use of intermittent pneumatic compression during the surgery and postoperative period").

Address for correspondence: Tomasz Urbanek, Department of General Surgery, Vascular Surgery, Angiology and Phlebology, Medical University of Silesia, Katowice, Ziolowa 45/47, 40-635 Katowice, Poland, e-mail: urbanek.tom@interia.pl 


\begin{abstract}
Although venous thromboembolism (VTE) is quite common in patients suffering from different stages of cancer, it is still an underestimated problem. Oncological treatment, surgeries, and advanced-stage cancer are only some risk factors for VTE, which is one of the most common causes of death in cancer patients. Differences in the risk of deep-venous thrombosis and its complications, including risk of bleeding, between particular oncological patient groups suggests that there is a need for individual risk assessment and prophylaxis dedicated to specific clinical situations and patients. They also give grounds for constant update of guidelines on prophylaxis in cancer patients. This document contains venous thromboembolism prophylaxis guidelines in oncology patients with focus on surgical cancer.
\end{abstract}

Key words: venous thromboembolism, cancer, cancer surgery, VTE prophylaxis, anti-cancer treatment

Acta Angiol 2016; 22, 3: 7I-102

\section{Introduction}

Venous thromboembolism affects various populations of patients, including those suffering from cancer who are at a higher risk of deep venous thrombosis and pulmonary embolism. Considering the need for actions aiming at decreasing the number of thromboembolic complication cases in cancer patients, this document presents guidelines based on up-to-date medical knowledge regarding recommendations and rules of antithrombotic treatment in cancer patients, especially those who are undergoing surgery on that account.

Proposed guidelines on venous thromboembolism apply to adult patients treated due to oncological reasons; please note that these guidelines do not refer to children. The guidelines are meant for medical professionals of different fields and medical workers participating in diagnostics and treatment of cancer patients. Up-to-date scientific data was analyzed along with guidelines on venous thromboembolism that have been published until recently in Poland and abroad with the focus on guidelines referring to cancer patients for their elaboration. Prophylaxis guidelines were formulated based on medicine based evidence (EBM) in order to form an universal document dedicated to cancer patients, who remain under supervision of a specialist, as well as those who are treated by general practitioners. The authors also attempted to adjust these guidelines as much as possible to the present healthcare system in Poland.

Guidelines represent the standpoint of the authors on most-justified diagnostic and therapeutic procedures, however, they should be interpreted in the context of each individual clinical situation. These guidelines should not be treated as mandatory treatment or a medical standard. Just like other guidelines, they are above all indications aiming to enable and facilitate rational clinical decisions regarding prophylaxis and treatment of venous thromboembolism in cancer patients. This document is based on scientific reports that are available at this moment. The authors of this work believe that it will require further updates along with new reports and study results that consider this issue.

Katowice, August I, 2016

\section{Methods, guidelines classification}

During the elaboration of this document all the available references were analyzed and guidelines were formulated based on definitions according to the GRADE Working Group (The Grading of Recommendations Assessment Development and Evaluation Scale). Formulated guidelines were classified as strong recommendations - [1] or weak recommendations - [2] and supported with an additional description referring to the quality of evidence that they have been based on. In the case of recommendations classified as strong, based on the analysis of results of correctly planned and performed studies, the authors are convinced that administration of a particular procedure will bring significant benefits in comparison to restraining from it (recommendation level I - "recommended"). In case of a weak recommendation (recommendation level 2 - "suggested") the authors believe that administration of the suggested procedures may be more beneficial than restraining from performing it. However, at this point, there are no high - quality studies that would determine favorable 
and unfavorable effects of a particular procedure this recommendation level should be considered as a suggestion for the final clinical decision.

According to the suggestions specified in GRADE, guidelines marked with letter $(A)$ are based on reports sufficient for formulating them and further studies probably will not elicit any changes. The letter (B) indicates that further studies could possibly influence the change of statement due to the quality of data available at this time. The letter $(C)$ suggests that due to very low quality of data available, further studies may elicit significant changes to the guidelines.

The levels of recommendation importance:

IA - strong recommendation, high-quality evidence according to EBM*;

IB - strong recommendation, moderate-quality evidence according to EBM;

IC - strong recommendation, low- or very low-quality scientific evidence;

$2 \mathrm{~A}$ - weak recommendation, high-quality evidence according to EBM (further studies probably will not have any significant influence on changes in suggested treatment method);

$2 \mathrm{~B}$ - weak recommendation, moderate-quality evidence according to EBM (further studies may have significant influence on changes in suggested treatment method);

2C - weak recommendation, low- or very low-quality scientific evidence (further studies probably will have significant influence on changes in suggested treatment method).

The authors reviewed papers on prophylaxis and the treatment of cancer patients using the MEDLINE database from January I, 1995 to January 3I, 2016. The analysis covered available randomized trials, prospective and retrospective studies, as well as meta-analysis, systematic reviews, and previously published Polish and foreign guidelines on prophylaxis and the treatment of venous thromboembolism (VTE), including VTE prophylaxis in cancer patients [4-3I].

\section{Chapter I. Venous thromboembolism prophylaxis - general recommendations}

According to up-to-date guidelines for prophylaxis and the treatment of venous thromboembolism (including: "Polish guidelines for the prevention and the treatment of venous thromboembolism - 20I2", "Antithrombotic Therapy and Prevention of Thrombosis, $9^{\text {th }}$ ed.: American College of Chest Physicians Evidence-Based Clinical Practice Guidelines - 20I2") the authors of guidelines for cancer patients stand by

*EBM — Evidence Based Medicine the general recommendations on prevention of thrombosis, formulated in the above-mentioned documents $[13,14]$ :

\section{Guideline I. I}

It is recommended to elaborate and implement guidelines for VTE prophylaxis in every hospital, department and/or institute, where the cancer patients at risk of venous thromboembolism are treated and consulted [IA].

\section{Guideline I.2}

It is recommended to elaborate guidelines for VTE prophylaxis on paper or in electronic form, as a standard procedure for particular health care facility [IC].

\section{Guideline I.3}

It is recommended to use anticoagulants for VTE prophylaxis and treatment according to manufacturer guidelines and drug registration documents [IC].

\section{Guideline I.4}

In patients with a high bleeding risk, benefits and risk of antithrombotic prophylaxis should be evaluated individually. In clinically justified situations, mechanical prophylaxis methods should be applied, until bleeding risk will decrease enabling the administration of pharmacological prophylaxis [IA].

\section{Comment}

Individual risk assessment of venous thromboembolism is justified considering the variety of clinical situations and differentiated characteristic of patients treated in particular health care facilities, and departments in view of treatment form, and risk factor characteristic of the particular patient's group. At the same time, significant differences between populations of patients indicate a need for the elaboration of an antithrombotic prophylaxis protocol dedicated to the particular patient group in each healthcare facility considering the characteristics of the treated population, as well as administered therapy. This protocol should be prepared on paper and in electronic form considering recommendations on risk assessment and prophylaxis of venous thromboembolism as well as up-to-date authorizations of available and administered drugs aimed for this indication. Guidelines on antithrombotic prophylaxis in the particular healthcare facility should be elaborated considering up-to-date guidelines, as well as an individual risk assessment for venous thromboembolism, treatment-related bleeding and potential complications caused by pharmacological prophylaxis in the particular group of patients. 


\section{Chapter 2. The prevention of venous thromboembolism in cancer patients treated surgically}

Venous thromboembolism often occurs in the natural course of cancer disease [32]. At the same time, however, attempts of treatment, especially surgical treatment, increase the risk of this complication [4, 9, $10,14,15,32,33]$. Surgery affects the risk of thrombosis through multiple factors; tissue trauma due to surgical procedures, periprocedural immobilization, blood and plasma substitution, positive pressure ventilation, potential inflammation foci or intravenous catheters [14, 34-39].

Patients qualified for surgery who are diagnosed with malignancy are three times as much in risk of deep vein thrombosis and twice in risk of pulmonary embolism as patients without a diagnosed cancer [34, 35, 40-44]. Because of oncological indications, in most cases of cancer patients qualified for surgical treatment, we should assume the population of these patients as high risk and very high risk of VTE [4, 14, I5]. The increased risk is also reflected in the proposed models of thromboembolic complication risk assessment, such as in the perioperative risk of VTE scale proposed by Caprini, in which the presence of cancer corresponds to 2 points (Table I) [15, 45-47].

According to current knowledge, while evaluating the risk of VTE, it is extremely important to take into consideration the presence of other risk factors, especially those related to the presence of comorbidities and a clinical condition causing an increased risk of VTE (obesity, prolonged immobilization, varicose veins, hormonal therapy, previous cerebrovascular event resulting in paralysis, prior episode of VTE and other) $[14,15,48]$. It must be emphasized that diseases recently defined as in the spectrum of nonsurgical medical fields, are among currently recognized risk factors of VTE. Among them are the worsening of chronic heart failure or inflammatory bowel diseases [14, 15, 21]. One should also keep in mind other potential risk factors, such as postsurgical infections - the presence of an intra-abdominal abscess or other infections of the surgical site following colorectal surgery or other acute infection may increase the risk of VTE [I5, 49-5I]. Merkow et al. analyzed the incidence of postsurgical VTE in cancer patients (a population of 44656 patients with 9 types of cancer) and documented that as $33.4 \%$ of cases with VTE occurred not immediately before the procedure, but right after discharge from the hospital (with varying proportions of patients with deep vein thrombosis depending on the type of cancer treated) [52]. Among other factors that significantly affect the incidence of VTE in this group, the following were re- cognized: age $\geq 65$ years, presence of metastases, high BMI, level of thrombocytes over 400000 , albumin level $<3.0 \mathrm{~g} / \mathrm{dL}$ and duration of the procedure being over 2 hours. VTE cases were more frequently observed in patients surgically treated for gastrointestinal tract, lung and prostate cancer, as well as in those patients with surgery performed on the ovaries/uterus. The fact that patients with an episode of VTE have a six times higher mortality rate is also worth noticing. Other authors also report a significant increased risk of VTE during remote periods of time post-surgery (after discharge). Alusbaie et al. analyzed retrospectively the results of 6612 "major" cancer surgery cases involving the abdominal and pelvic areas and identified $4.05 \%$ of symptomatic VTE up to 90 days after treatment, of which $47.5 \%$ to be diagnosed after discharge [53]. Prior cancer therapy including chemotherapy and presurgical radiotherapy influence the general risk of thrombosis [54].

However, not only cancer surgery in the abdominal, pelvic and thorax areas is linked to risk of thrombosis. Reports of VTE occurrences are followed by other cancer surgery procedures of the head and neck, which include oral and maxillofacial surgery procedures or also commonly performed breast cancer surgery [55-60]. According to Tran et al. the risk of overt VTE in a population of 49028 patients undergoing mastectomy amounted to $0.23 \%$ [58]. Similar data was presented by De Martino et al. suggesting the presence of $0.19 \%$ of symptomatic deep vein thrombosis, pulmonary embolism $0.12 \%$ and $0.28 \%$ of VTE within 30 days after breast cancer surgery [59]. Lovely et al. report about $0.5 \%$ of cases of VTE in patients undergoing surgery for breast cancer reasons [60]. The authors of the above-mentioned studies also point to potential risk factors in this population other than just cancer presence [58-60].

The effectiveness of low doses of heparin (low doses of unfractionated heparin - LDUH) in the prevention of VTE in high risk surgical patients has been documented for many years, however, in everyday clinical practice, partly of practical reasons, this method of prophylaxis plays a marginal role in comparison with the very common use of the low molecular weight heparin $(\mathrm{LMWH})$ in this indication [6I-70]. In controlled randomized trials comparing LMWH with LDUH in patients undergoing cancer surgical treatment, both methods of prevention have a high and comparable efficacy [68, 7I]. Comparative studies on the efficacy of unfractionated and low molecular weight heparin in VTE prevention in the perioperative period in the cancer patients were evaluated in a meta-analysis involving 16 prospective clinical trials performed on a total population of 12890 patients [72]. The use of LMWH compared to LDUH was associated with a similar mortality rate (RR 0.89; 
Table I. Modified Caprini scale to assess the risk of thromboembolic complications in surgical patients [according to I5]

\begin{tabular}{|c|c|c|c|}
\hline I point & 2 points & 3 points & 5 points \\
\hline $\begin{array}{l}\text { Age } 4 \text { I-60 years } \\
\text { Small surgery } \\
\text { BMI > } 25 \mathrm{~kg} / \mathrm{m}^{2} \\
\text { Edema of the lower limbs } \\
\text { Varicose veins of the lower } \\
\text { limbs } \\
\text { Pregnancy or postpartum } \\
\text { period } \\
\text { Or a history of unexplained } \\
\text { recurrent miscarriages } \\
\text { Oral contraceptives or hor- } \\
\text { mone replacement therapy } \\
\text { Sepsis (< I month) } \\
\text { An acute lung disease, } \\
\text { including pneumonia } \\
\text { (< I month) } \\
\text { Lung disorders } \\
\text { Acute myocardial infarction } \\
\text { Exacerbation or diagnosis of } \\
\text { heart failure (< I month) } \\
\text { History of inflammatory } \\
\text { bowel disease } \\
\text { The patient is undergoing } \\
\text { conservative treatment, } \\
\text { remains in bed }\end{array}$ & $\begin{array}{l}\text { Age } 6 \mathrm{I}-74 \text { years } \\
\text { Arthroscopic surgery } \\
\text { Major surgery (> }>5 \mathrm{~min}) \\
\text { Laparoscopic surgery } \\
\text { (> } 45 \mathrm{~min}) \\
\text { Cancer } \\
\text { Remaining in bed (> 72 h) } \\
\text { Plaster cast with immobili- } \\
\text { zation } \\
\text { Central venous catheter }\end{array}$ & $\begin{array}{l}\text { Age } \geq 75 \text { years } \\
\text { History of VTE } \\
\text { VTE in family history } \\
\text { Factor V Leiden } \\
\text { G202 IOA prothrombin gene } \\
\text { mutation } \\
\text { Lupus anticoagulant } \\
\text { Anticardiolipin antibodies } \\
\text { Anti- } \beta_{2} \text {-GPI } \\
\text { Increased levels of serum } \\
\text { homocysteine } \\
\text { Heparin-induced thrombo- } \\
\text { cytopenia (HIT) } \\
\text { Other congenital or acquired } \\
\text { thrombophilia }\end{array}$ & $\begin{array}{l}\text { Stroke }(<\text { I month) } \\
\text { Elective arthroplasty } \\
\text { Fracture of the pelvis, femur } \\
\text { or shin bone } \\
\text { Acute spinal cord injury } \\
(<\text { I month) }\end{array}$ \\
\hline
\end{tabular}

Scoring: 0 points — very small risk; I-2 points — low risk; $3-4$ points — average risk; $\geq 5$ points — high risk

95\% Cl 0.74-I.08), similar incidence of pulmonary embolism (RR: $0.73 ; 95 \% \mathrm{Cl}$ 0,34-I. 54), similar rate of symptomatic deep vein thrombosis (RR: $0.50 ; 95 \% \mathrm{Cl}$ 0.20-I.28) and a similar incidence of "major" bleeding complications (RR: 0.85; 95\% Cl 0.52-I.37) [72].

When using LDUH and LMWH in DVT prophylaxis in surgical oncology, according to indications as well as previously performed research, pharmacological prophylaxis should begin prior to the surgical procedure $[4,9,68,70]$. So far, there are no reports of clinical trials or the registration of any new oral anticoagulants in thrombosis prophylaxis both in the field of surgery and surgical oncology.

Apart from the time of the start of the prophylaxis, an important issue concerning perioperative VTE prophylaxis in cancer patients is the heparin dose and duration of prophylaxis. The authors of this document agree that it is crucial to adhere to the registration documents of certain drugs and use them as indicated in those documents. Some of the products containing LMWH have a choice of different prophylactic dosage options for the moderate and high risk surgical patients, however, there are suggestions supported by research that higher doses should be used in high and very high risk cancer patients. In a study of 1.375 patients, of whom $70 \%$ were patients with cancer, two prophylactic doses of dalteparin ( $2500 \mathrm{U}$ and $5000 \mathrm{U}$ ) were used. The dose $5000 \mathrm{U}$ was more effective in preventing postoperative VTE than the $2500 \mathrm{U}$ dose (postoperative VTE of $8.5 \%$ vs. $14.9 \%$; $<<0.00$ I) [73].

Currently, there are still very few randomized prospective studies comparing the efficacy of the different LMWHs in this indication. In the SAVE-ABDO study, in which more than $80 \%$ of the 44 I 4 patients were those who undergo major surgery in the abdominal area due to cancer, the patients were randomized to the groups receiving enoxaparin or semuloparin (the beginning of prophylaxis in both groups before the procedure). Endpoints defined in this study as an episode of VTE or death occurred in $5.5 \%$ of patients receiving enoxaparin and in $6.3 \%$ of those receiving semuloparin (OR I. I6; $95 \% \mathrm{Cl}, 0.84-1.59)$ with a smaller percentage of bleeding complications in the group receiving semuloparin [74]. In a study comparing the efficacy of nadroparin 
or enoxaparin at prophylactic doses (nadroparin: $2850 \mathrm{U}$ anti-Xa, enoxaparin $4000 \mathrm{U}$ anti-Xa) in surgical patients with colo-rectal cancer, symptomatic or asymptomatic DVT or pulmonary embolism occurring up to 12 days of observation, was diagnosed respectively in $15.9 \%$ and $12.6 \%$ of those patients (RR I.27; $95 \% \mathrm{Cl} 0.93$ to 1.74 , $\mathrm{p}=\mathrm{NS}$ ) with fewer major bleeding complications in the group treated with nadroparin (7.3\% vs. I I.5\%; $p<0.05)$ - in this context, from a methodological standpoint one must notice that administering enoxaparin in a dose of $40 \mathrm{mg}$ (respectively 2, instead of the currently recommended 12 hours before surgery) differed from what is indicated now by the manufacturer [75]. The comparison of dalteparin in a dose of $5000 \mathrm{U}$ anti-Xa with fondaparinux $2.5 \mathrm{mg}$ administered once a day for 5 to 9 days revealed comparable indicators of benefits/ /risk for both drugs in perioperative prophylaxis in surgical patients [76]. In the case of fondaparinux, however, there is still a lack of prospective, randomized studies dedicated specifically to the population of cancer patients - in the mentioned above PEGASUS study, they represented only a small portion of the population studied [76, 77].

In most of the above mentioned research in patients undergoing major surgery in the abdominal and pelvic area, including surgical oncology, thrombosis prophylaxis was administered up to 7-10 days after surgery, which according to current knowledge may be insufficient [4, $14,32,33]$. Conclusions from randomized clinical trials that relate to extended (up to 4 weeks) primary VTE postsurgical prophylaxis (ENOXACAN II — extended prophylaxis after major surgery in the abdominal and pelvis area; FAME - extended prophylaxis in extensive surgery of the abdominal and pelvis area) indicate potential benefits of such management of surgical patients at high risk of thromboembolic complications $[78,79]$. In both studies, 4 weeks of thromboembolic prophylaxis with low molecular weight heparin proved to be an effective means to reduce the incidence of VTE compared to the standard duration of prophylaxis (at the same time not increasing the percentage rate of bleeding) $[78,79]$. At the moment, it should be considered rational to extend VTE prophylaxis with LMWH up to 4 weeks in patients undergoing extensive cancer surgery in the abdominal and/or pelvic areas and at a low risk of bleeding complications [78-82].

Rapid and aggressive mobilization of the patients after surgery is currently the standard of perioperative care. Often other mechanical methods of thromboprophylaxis are also used. A number of already completed studies related to surgically treated patients highlight the beneficial effects of mechanical prophylaxis methods on the reduction of VTE incidence in this group of patients [14]. Most of them, however, relate only to mixed groups of patients, in terms of risk as well as in terms of indications for surgery. Reports dedicated to homogenous groups of cancer patients are very limited [77, 83-87].

According to available literature and most previously published guidelines, mechanical methods should not be used as the only thromboprophylaxis method in patients with a high risk of VTE under condition, however, that the patient is at low risk of bleeding complications which is a potential contraindication for pharmacological prophylaxis $[4,9,14,15]$. On the other hand, concomitant prophylaxis with mechanical methods, in particular intermittent pneumatic compression (IPC), may have a beneficial additive effect on the reduction of thrombotic events in patients with a high and very high risk of VTE qualified for surgery [4, 9, I4, I5]. In a meta-analysis, the results of 25 prospective randomized clinical trials concerning the combined DVT prophylaxis based on anticoagulation and mechanical methods were compared with VTE prevention regimens using only one method of prophylaxis [88]. Based on this report, pharmacological prophylaxis with mechanical methods together resulted in $49 \%$ DVT risk reduction. On the other hand, an increased bleeding risk should also be considered when pharmacological prevention is used The pharmacological VTE prophylaxis added to mechanical methods led to the $44 \%$ DVT risk decrease, however, a significant increase in the bleeding rate was observed (RR I.74; I.29-2.34) [88].

\section{Laparoscopic oncological surgery}

Data on effectiveness of VTE prophylaxis in laparoscopic oncological surgery is limited [89-9I]. Xie et al. in their meta-analysis of 9 randomized clinical trials conducted on 2606 cases of colorectal cancer, who underwent surgery, did not find any difference in DVT incidence between patients treated with open or laparoscopic surgery [9I].

The guidelines of the Society of American Gastrointestinal and Endoscopic Surgeons dedicated to patients undergoing laparoscopic surgery and up-todate guidelines of other scientific societies emphasize that there are no prospective clinical trials of sufficient quality focusing on antithrombotic prophylaxis in cancer patients treated with laparoscopic surgery [9, 14, 92]. Factors related to laparoscopic surgery that increase the risk of thromboembolic complications include laparoscopic pelvic surgery, as well as long-duration of the surgery time (above I h) [92]. In addition, the presence of cancer, anticancer therapies and other VTE risk factor presence should be taken into consideration $[9,14,92]$.

Due to a small number of studies focusing on the method and best possible timespan of thrombopro- 
phylaxis in patients undergoing laparoscopic oncological surgeries, thus far it is only possible to extend the guidelines referring to the open surgeries. The benefits of prolonged antithrombotic prophylaxis at least in some patients undergoing laparoscopic oncological surgery are confirmed by Vedowatti et al. in the study conducted on 225 patients after laparoscopic colorectal surgery (93). The patients were randomly assigned to the group with pharmacological VTE prophylaxis administered for $8 \pm 2$ days or to the group, where prophylaxis was prolonged to 4 weeks. The effectiveness of prevention was checked by venous ultrasound imaging. No statistically significant differences were found in the incidence of bleeding complications. However, prolongation of antithrombotic prophylaxis up to 4 weeks significantly reduced DVT rate detected by the means of ultrasound (DVT rates: $9.7 \%$ in the short-term prophylaxis group vs. $0 \%$ in the long-term prophylaxis group) [93].

\section{Guidelines \\ Venous thromboembolism prophylaxis in cancer patients undergoing surgical procedures}

\section{Guideline 2.I}

The VTE risk as well as the risk of hemorrhagic complications should be individually assessed in each patient undergoing cancer surgery [IA].

\section{Guideline 2.2}

All patients undergoing extensive oncological surgeries in the abdomen and pelvis should receive VTE prophylaxis with prophylactic doses of low-molecular-weight heparin or low doses of unfractionated heparin $(3 \times 5000 \mathrm{U})$, if there are no contraindications, including active bleeding or high risk of bleeding events [IA].

\section{Guideline 2.3}

Patients suffering from active cancer and at high risk of VTE undergoing other surgeries, who are not at high risk of serious bleeding complications, should receive pharmacological prophylaxis with low-molecular-weight heparin in the dose that is adequate to the VTE risk or low doses of unfractionated heparin (5000 U every 8 h s.c.) [IA].

\section{Guideline 2.4}

If bleeding risk is not high in cancer patients with moderate VTE risk undergoing other surgical procedures than extensive surgery, it is recommended to administer thromboprophylaxis with low-molecu- lar-weight heparin or low doses of unfractionated heparin according to the current risk assessment for VTE and up-to-date drug authorizations [IB].

\section{Guideline 2.5}

It is suggested that in cancer patients qualified for surgery, who are at high or very high risk of venous thromboembolism, pharmacological prevention should be supported with mechanical methods, most preferably intermittent pneumatic compression [2C].

\section{Guideline 2.6}

It is not recommended to use mechanical methods as the only prevention for thromboembolism (without pharmacotherapy) in surgical cancer patients, who are not at higher risk of bleeding [IB].

\section{Guideline 2.7}

In surgical patients at high risk of serious bleeding complications or in patients with contraindications for pharmacological prophylaxis due to active bleeding and high risk of bleeding relapse, mechanical prophylaxis should be considered (most preferably intermittent pneumatic compression), at least until the bleeding risk decreases and administration of pharmacological prophylaxis is possible [2C].

\section{Guideline 2.8}

In patients undergoing cancer surgery VTE prophylaxis should be continued for a minimum of 7-10 days [2B]. Patients undergoing major cancer surgery in the abdominal cavity and/or pelvis, who are not at high risk of serious bleeding complications and have VTE risk factors such as prolonged immobilization, obesity, history of VTE, or other DVT risk factors, are recommended to receive prolonged pharmacological prophylaxis (4 weeks) with low-molecular-weight heparin [2B]. In the other cases, the decision regarding prolongation of prophylaxis should be made individually based on benefits and risk of such treatment [2C].

\section{Guideline 2.9}

In laparoscopic cancer surgery performed within the abdomen and pelvis it is suggested to assess the risk of VTE individually [IA] as well as to use the same principles of thromboprophylaxis as in patients operated by the means of laparotomy performed because of cancer [2C].

\section{Guideline 2.I0}

Cancer patients who are at high risk of thromboembolic complications and undergo surgery should not undergo inferior vena cava filter placement for primary antithrombotic prevention [2C]. 


\section{Chapter 3. Specific guidelines regarding cancer patients in selected surgical fields}

Guidelines presented in Chapter 2 are dedicated to oncological surgical patients and contain the rules of prophylaxis in oncological surgery. For practical implementation of the proposed guidelines, it is necessary to take into account the characteristics of the treated patient population and the differences arising from the different bleeding risk, as well as the type of procedures performed. In order to provide guidelines in the most practical option, the authors analyzed recommendations available in the literature and proposed detailed guidelines for patients undergoing cancer surgery in the chosen surgical specialities such as: thoracic surgery, gynecology, neurosurgery, and urology.

\section{I. VTE prophylaxis in patients undergoing thoracic cancer surgery}

Lung cancer is associated with a high risk of thromboembolic complications. Patients undergoing major thoracic surgery because of cancer (including extensive lung resection, pneumonectomy, resection of the lung and pleura, or esophageal oncological resection) should be classified as at high risk of VTE [14,94-97]. On the other hand, due to the still limited number and quality of available studies, data on the efficacy and risk of thromboprophylaxis in patients undergoing thoracic surgery is limited, and therefore formulated recommendations are based largely on reports relating to general surgery procedures [14, 15].

In studies based on retrospective assessment of VTE incidence, clinically symptomatic venous thromboembolism was found in $1.2-5.2 \%$ of patients undergoing thoracic surgery and the incidence of VTE was higher in patients with lung cancer [94, 95]. In the study performed by Dentali et al. on 693 patients, who underwent thoracotomy due to lung cancer, despite the routine use of prophylaxis with LMWH or LDUH, symptomatic VTE was diagnosed in $1.7 \%$ of patients, including pulmonary embolism in $1.3 \%$ of patients, and fatal pulmonary embolism in $0.6 \%$ [98]. Kalweit et al. in the study evaluating the results of treatment of 1735 patients, who underwent oncological lung resections, fatal pulmonary embolism was diagnosed post mortem in $1.2 \%$ of patients (despite the use of thromboprophylaxis in the majority of the studied population) [99]. Similar data was obtained in another retrospective analysis, in which the risk of clinically symptomatic VTE within 3 months in 13000 patients undergoing major lung resections due to cancer amounted to $1.6 \%$ [100].

The incidence of VTE in the prospective studies evaluating VTE occurrence after cancer thoracic surgery appears to be significantly higher [14, 95, 101, 102]. Hachey et al. reported $5.2 \%$ of the cases of diagnosed VTE in patients undergoing thoracic surgery due to lung cancer within 60 days after operation, $1 / 3$ of whom was diagnosed after discharge [103]. In a prospective clinical study conducted on 336 patients after pneumonectomy due to cancer, the risk of symptomatic VTE amounted to $7.4 \%$ despite the use of thromboprophylaxis with low-dose unfractionated heparin, as well as intermittent pneumatic compression [104]. Weder et al. in the study evaluating outcomes of 176 pneumonectomies performed due to lung cancer conducted after preoperative chemotherapy found a mortality rate of $3 \%$, half of which was associated with the pulmonary embolism occurrence [102]. In their research Schugarbecker et al. evaluated the results of surgical treatment of $328 \mathrm{pa}-$ tients with pleural mesothelioma. Symptomatic VTE occurred within the first month after surgery in $7.9 \%$ of patients, whereas fatal pulmonary embolism in $1.2 \%$ of cases [104].

In the systematic review evaluating the results of 19 studies, which included 10660 patients undergoing thoracic surgery because of lung cancer, the incidence of VTE amounted to $2.0 \%$ (range $0.2-19 \%$ ) [105]. In a retrospective analysis performed in 2013 , which included 6004 patients undergoing elective thoracic surgery in the context of pharmacological thromboprophylaxis based on VTE risk assessment, Gómez-Hernández et al. found that VTE occurred in $0.18 \%$ of cases. However, in this study only part of the patients were qualified for surgery due to cancer, and the risk of symtomatic VTE after pneumonectomy was significantly higher than in less extensive operations and amounted to $1.31 \%$ [106].

Like in other medical fields more extensive thoracic surgery generates higher risk of thrombotic complications. According to Swiniarska et al. pneumonectomy involves both, a significantly higher risk of VTE and stronger activation of the coagulation system than in lobectomy performed due to lung cancer at stage I and 2 [107]. The following specific risk factors that increase the risk of VTE are important in this patient group: the very presence of cancer and the type as well as the grade of the tumor, non-radical resection of the tumor, postoperative use of anti-angiogenic agents, small-molecule inhibitors, tyrosine kinase inhibitors, EGFR and preoperative increase in D - dimer levels [108]. Other important risk factors in the lung cancer patients are radiotherapy and chemotherapy. Kodlec et al. in the population of 950 patients suffering from lung cancer found VTE in $17.6 \%$ of cases in the group of surgical patients and $\mathrm{I} I \%$ and $48 \%$ of VTE cases in patients undergoing radio- and chemotherapy respectively [109].

Compared to studies relating to the symptomatic VTE, the percentage of asymptomatic VTE patients 
qualified for extensive thoracic surgery, including cancer thoracic surgery, is significantly higher [ I I0-1 |4]. Based on the fibrinogen uptake test a high rate of DVT cases was reported (18-51\%) in patients undergoing lobectomy or pneumonectomy without thromboprophylaxis [ I 14]. Slightly lower values of asymptomatic DVT incidence were found in the ultrasound based studies in the thoracotomy patients (4-14\%) [ II4].

In the evaluation of the risk and benefits of thromboprophylaxis, bleeding risk should be assessed [14]. In the analysis of the large population concerning almost 17000 patients undergoing lung resection, the need for reoperation due to bleeding complications was $1 \%$, with a significantly higher incidence of reoperation in the group of over I 200 patients undergoing pneumonectomys (5\%) [ I I5].

There is limited data related to the prospective randomized clinical studies on the use of pharmacological thromboprophylaxis in cancer thoracic surgery [ 112 , I I3, I |6-I |8]. Di Nisio et al. evaluated the safety and efficacy of primary thromboprophylaxis in patients after thoracic surgery, based on the analysis of the available prospective studies in the field of thoracic surgery. It should be pointed out that the studied groups of patients in particular clinical trials included only some patients diagnosed with cancer, and differed between each other, in terms of both, indications for surgery as well as the extensity of surgery performed [ I 18]. In 6 clinical trials evaluating the efficacy of pharmacological thromboprophylaxis 15 cases of pulmonary embolism were identified among 2890 surgical patients (0.51\%). In this analysis, bleeding complications were observed after administration of low-molecular-weight heparin (LMWH at constant doses vs. LMWH doses adjusted to the weight — bleeding rate: $2.7 \%$ vs. $8.1 \%$ RR 0.33 ; $95 \% \mathrm{Cl}: 0.07-1.60$ ) as well as after application of LDUH (bleeding rate - 6\%) [II8]. Based on the above analysis, the authors formulated conclusions suggesting a need for individual evaluation of both, the risks of thromboembolic complications and bleeding complications in each patient eligible for thoracic surgery.

\section{Guidelines \\ VTE prophylaxis in patients undergoing thoracic cancer surgery}

\section{Guideline 3.I.I}

In all patients undergoing thoracic surgery due to cancer, individual assessment of VTE risk as well as bleeding risk is recommended [IA].

\section{Guideline 3.I.2}

In the case of high risk of VTE and when there is low high risk of serious bleeding complications in patients undergoing thoracic cancer surgery, it is recommended to use $\mathrm{LMWH}$ [IB] or LDUH [IB] more than not using any pharmacological prophylaxis at all. At the same time, in patients at high and very high risk of VTE it is suggested to support pharmacological prophylaxis with mechanical methods (most preferably intermittent pneumatic compression - IPC) [2C].

\section{Guideline 3.I.3}

In cases of moderate risk of VTE and when there is no high risk of serious bleeding complications in cancer patients undergoing thoracic surgery, it is recommended to use LMWH [2B], LDUH [2B] or mechanical methods (most preferably intermittent pneumatic compression - IPC) [2C] more than not using any prophylaxis at all.

\section{Guideline 3.I .4}

Patients undergoing thoracic surgery due to cancer who are at high risk of both VTE and bleeding complications, should be the candidates for mechanical methods of prophylaxis (preferably with the use of intermittent pneumatic compression - IPC), at least until the risk of bleeding decreases so that it is possible to start pharmacological prophylaxis [2C].

\subsection{Thromboprophylaxis in patients un- dergoing gynecological cancer surgery}

The incidence of deep venous thrombosis and pulmonary embolism after major gynecological surgery corresponds with the one observed in patients undergoing general surgery, and the presence of cancer significantly increases the risk of VTE in this group of patients [14, 15, I 14]. Clinical trials on gynecological surgery performed due to cancer suggest that the incidence of VTE ranges from 0 to $14.8 \%$ of women, who used different forms of thromboprophylaxis, up to over $35 \%$ in patients without prophylaxis [1 19]. The incidence of symptomatic VTE is significantly different in the studied populations, depending on the indications for surgical treatment as well as the extent and method of operation. Minimally invasive laparoscopic procedures are associated with a significantly lower risk of VTE than the extensive oncological surgeries performed in highly thrombogenic cancers such as ovarian cancer [120-123]. In a large group of 4 I 58 patients underwent gynecological cancer surgery the tumor most commonly associated with VTE occurrence was ovarian cancer [124]. This is also confirmed by other reports that suggest a high incidence of VTE in the course of ovarian cancer and that a significant number of thromboembolic events in this type of cancer occur even before cancer is diagnosed and in as many as $4.8-20 \%$ of patients at the time of diagnosis [125-127]. 
Despite growing awareness of VTE incidence in a population of patients undergoing gynecological cancer surgery, the number and quality of randomized clinical trials dedicated to this group of patients remains limited $[14,128-133]$. Because there is still a small number of randomized studies conducted on patients, who underwent gynecological surgery, in particular, cancer surgery, the current recommendations in gynecological surgery are largely based on extrapolation of guidelines for patients undergoing general surgery $[14,15]$.

Taking into account the characteristics of this medical field, the relevant risk factors should additionally include, aside from the ones generally accepted for surgical patients, an abdominal access in comparison to transvaginal access, treatment extended to pelvic lymphadenectomy as well as earlier irradiation of this area. Hormonal therapy may also be important in terms of an increased VTE risk. Other factors such as age, obesity, blood transfusions or previous VTE episodes correspond with the risk factors found in surgical patients [14].

In available randomized trials a significant reduction of deep venous thrombosis incidence in major gynecological surgery was documented as a result of low-dose unfractionated heparin use [133]. However, only some of the patients taking part in the research included above were operated due to oncological reasons. In studies comparing the efficacy of low-dose unfractionated heparin and prophylactic doses of low molecular weight heparin in gynecologic oncology surgery, there were no significant differences in both, the occurrence of VTE, as well as the percentage of bleeding, between the two methods of prophylaxis [68, I34-I37].

Although a relatively smaller rate of thromboembolic complications is reported in minimally invasive surgery, data on the effectiveness of VTE prevention in case of gynecologic laparoscopic procedures performed due to oncological reasons remains extremely limited and does not allow, at present, to define separate rules for the prophylaxis in laparoscopic surgery for this condition [137-|40].

In a systematic review of literature, II randomized clinicaltrials related to the use of low molecular weight heparin and intermittent pneumatic compression in gynecologic cancer surgery were identified [I4I]. In the analysis of the studies on the effectiveness of the low-dose unfractionated heparin, a significant decrease in the incidence of DVT in the comparison to the control group $(R R=0.58,95 \% \mathrm{Cl} 0.35-0.95)$ in this clinical settings was reported. In a group of 340 patients in which the efficacy of low-dose unfractionated heparin and low-molecular-weight heparin in this indication was compared, no significant differences in DVT occurrence between the two groups was noticed [I4I]. It should be emphasized that, the use of heparin in the prevention of cancer patients undergoing gynecological surgery has proven more effective when applied in three subcutaneous injections than its usage twice a day $[131,142,143]$.

Similar to general surgery patient population, there are also reports suggesting a high efficacy of intermittent pneumatic compression in patients referred to gynecological cancer surgery [14, 143, 144]. Research conducted by Maxwell et al. related to $21 \mathrm{I}$ patients undergoing gynecological cancer surgery compared the results of thromboprophylaxis by the means of $\mathrm{LMWH}$ and IPC - in both groups no cases of symptomatic VTE and only 3 cases of asymptomatic ultrasonographically proven proximal DVT cases (in examination performed 3-5 days after surgery) were found [145].

Data justifying extending the duration of thromboprophylaxis in cancer patients suggests a beneficial effect of extending prophylaxis with LMWH in patients undergoing extensive oncological surgery in the abdomen and pelvic area without a significant increase in risk of bleeding [14]. So far, in the studies on this issue, gynecology patients operated because of oncologic indications were only a small percentage of the overall studied group (ENOXACAN II - $8 \%$ of the 332 randomized patients) and potentially available recommendations for this group of patients are based on guidelines for surgical patients [78].

The fact that a limited number and the low quality of research on gynecological surgery including cancer surgery is mentioned in ACCP 2012 guidelines, the common recommendations for patients undergoing surgical and gynecological treatment are proposed [14]. The authors having noticed this problem see the need for further research dedicated to oncological patients operated due to gynecological indications.

\section{Guidelines \\ VTE prophylaxis in gynecological cancer surgery}

\section{Guideline 3.2.I}

In all patients undergoing gynecological cancer surgery, individual assessment of VTE risk as well as bleeding risk is recommended [IA].

\section{Guideline 3.2.2}

In cancer patients undergoing major oncological surgery due to gynecological indications in the area of the pelvis and abdominal cavity, VTE thromboprophylaxis with prophylactic doses of low molecular heparin or low doses of unfractionated heparin is recomended, as long as there are no contraindications which include active bleeding or a high risk of bleeding complications [IA]. 


\section{Guideline 3.2.3}

Unless there is a high risk of serious bleeding complications in patients with cancer and a moderate risk of venous thromboembolism undergoing surgery other than major surgery it is recommended to administer VTE prophylaxis by the means of low-molecular-weight heparin or low doses of unfractionated heparin according to the current VTE risk assessment evaluation [IB].

\section{Guideline 3.2.4}

In cancer patients qualified for surgery who are at high or very high risk of VTE it is suggested to support pharmacological prophylaxis with mechanical methods - most preferably with the use of intermittent pneumatic compression [2C].

\section{Guideline 3.2.5}

In patients undergoing gynecological cancer surgery who are at high risk of serious bleeding complications or in those patients who have contraindications to administer pharmacoprophylaxis due to active bleeding or high risk of bleeding recurrence, mechanical prevention, most preferably by the means of intermittent pneumatic compression should be considered at least until the risk of bleeding is reduced and start of pharmacological prophylaxis is possible [2C].

\section{Guideline 3.2.6}

In patients undergoing cancer gynecological surgery VTE prophylaxis should be continued for at least 7-10 days [2B]. In patients undergoing major gynecological cancer surgery, who are not at a high risk of serious bleeding complications with the presence of VTE risk factors such as prolonged immobilization, obesity, history of previous VTE or other thrombosis risk factors, it is suggested to use the prolonged pharmacological prophylaxis (4 weeks) with low molecular weight heparin. [2C] In all other cases the decision concerning the extended of the prophylaxis duration prevention must be taken individually while assessing the risk/benefits ratio [2C].

\section{Guideline 3.2.7}

In the case of gynecologic laparoscopic cancer surgery it is suggested to perform an individual VTE risk assessment [IA] as well as to use the same patterns of thromboprophylaxis as in the patients undergoing laparotomy due to cancer indications [2C].

\section{Guideline 3.2.8}

Gynecological cancer patients undergoing surgery, who are at a high risk of thromboembolic complications should not undergo inferior vena cava filter placement for primary antithrombotic prevention [2C].

\subsection{VTE prophylaxis in neurosurgical cancer patients}

Venous thromboembolism is one of the most significant complications in the population of the neurosurgical cancer patients and its prevalence is related to the type of performed surgery, perioperative immobilization and the tumor itself [14, 146-149]. Both, intra-cranial surgery and a malignant tumor presence significantly increase the risk of local bleeding complications [14, I50, I5I].

Studies of limited quality on antithrombotic prophylaxis in the field of cancer neurosurgery indicate that the risk for venous thromboembolism is high when no prophylaxis is administered [150-152].

Available studies on thrombosis prophylaxis in neurosurgery suggest the possibility to reduce the VTE risk effectively by the means of mechanical methods, as well as pharmacological prophylaxis [150-152]. However, most of these reports apply to the patients operated not only due to cancer. Prospective trials on effectiveness and safety of thrombosis prophylaxis in the oncological patient population undergoing neurosurgery are still very rare [150].

Studies on patients, who did not receive anithrombotic prophylaxis proved that craniotomy due to the tumor presence corresponds with a risk for symptomatic VTE of, at least, $10 \%$, which qualifies them as at a very high risk for thromboembolic events [14]. Smith et al. in a retrospective analysis of I | 48 neurosurgical resections performed due to intracranial tumors estimated the DVT incidence at $13.7 \%$ and pulmonary embolism at $3.3 \%$ [153]. The team working in the same health care facility analyzed also the results of surgical treatment in 336 patients with malignant glioma and reported VTE incidence at $15.7 \%$ [154].

According to the literature, VTE risk in patients suffering from malignant glioma is exceptionally high in subjects, who underwent craniotomy and surgical treatment, ranging from 21 to $32 \%$, whereas deep venous thrombosis occurs in 3-25\% of cases [155-161].

Most studies focusing on thrombosis prophylaxis analyze heterogeneous groups of neurosurgical patients, among whom only some suffered from a malignant tumor of the central nervous system. The report based on the analysis of 200 neurosurgical patients estimated the average risk of symptomatic VTE within 30 days of follow-up examination at $3.9 \%$. However, the risk was significantly higher in patients, who underwent craniotomy due to a primary brain tumor $(7.5 \%)$ or brain metastases $19 \%$. In this study $67 \%$ of the patients received antithrombotic prophylaxis [162]. 
It should be emphasized that craniotomy patients, who were not diagnosed with a tumor, are also at high risk of VTE, and the VTE risk does not only correspond with the type of surgery performed but also with concomitant risk factor presence [14]. Besides the very presence of the tumor, VTE risk factors in patients who undergo craniotomy due to the oncological reasons, include: the type and stage of the cancer, advanced age, long surgery duration, non-radical tumor resection, prolonged immobility, paresis of limb/limbs, chemotherapy, corticosteroid administration, and the presence of central catheters [14, 155, 159, 160, 163]. Kimmel et al. specified the following VTE risk factors in patients undergoing craniotomy (in their study $56 \%$ of 3098 patients underwent craniotomy due to mailgnancy): poor functional performance, age $>60$ years, surgery duration $>4$ hours, and postoperative complications such as: pneumonia, cerebrovascular events, sepsis, septic shock, unplanned and/or prolonged intubation [164].

Administration of appropriate prophylaxis for VTE prevention in neurosurgical patients, including those who were operated because of a tumor, requires an individual bleeding risk assessment in the context of disease etiology, projected surgery, and particular VTE prevention method. Postoperative intracranial bleeding requires further consideration. The review of 20 studies performed on 31,000 craniotomy patients at total, who did not receive VTE prophylaxis suggests that the risk of intracranial bleeding amounts on average to $1.1 \%$, however. the differences are significant depending, among others, on what the indication for surgery was [15I].

Application of mechanical methods of VTE prophylaxis in neurosurgical patients is a focus of interest, especially for procedures having a high bleeding risk, including neurosurgical oncological procedures [ 14 , 150, 15I]. Apart from early patient mobilization, which is not always possible, mechanical methods of prophylaxis available for this group include intermittent pneumatic compression (IPC), graduated compression stocking, and electric calf muscle stimulation. In two trials, the effectiveness of IPC was compared with controls, who did not receive any prophylaxis. The studies proved that IPC is beneficial for neurosurgical patients $[165,166]$. Turpie et al. compared the effectiveness of IPC with the absence of any prophylaxis in the group of patients, among whom $51 \%$ suffered from a brain tumor [165]. Based on the fibrinogen uptake test, the authors found that deep venous thrombosis dropped from $23.5 \%$ to $1.5 \%$. Skilman et al. studied the effectiveness of antithrombotic prophylaxis in patients $69 \%$ of whom suffered from brain tumors. They observed a reduction in VTE incidence in patients who received IPC treatment from $25 \%$ to $8.3 \%$ [166].
Graduated compression stockings are usually more commonly used for VTE mechanical prophylaxis than IPC because of many reasons, including economic ones. However, data regarding their effectiveness, when used as a single prevention method in patients undergoing oncological neurosurgical procedures are limited and controversial. Bucci et al. in a study conducted on a small group of neurosurgical patients, among whom $56 \%$ suffered from brain tumors, did not find any significant difference in the incidence of symptomatic deep venous thrombosis between patients using intermittent pneumatic compression and those using gradated compression stockings [167]. Angelli et al. conducted a study comparing outcomes of graduated compression stockings used along with enoxaparin and graduated compression stockings used with placebo. In the research arm where only compression stockings were used, the thrombosis incidence amounted to $33 \%$ (evaluation based on phlebography) [168]. In this trial, opposed to the previous one, patients with brain or spinal cord tumors constituted $97 \%$ of analyzed population. The study conducted by Turpie et al. on the incidence of asymptomatic deep venous thrombosis also confirmed that differences in characteristics and risk rates between analyzed neurosurgical patient populations are significant [169]. Deep venous thrombosis was diagnosed in $8.75 \%$ of patients using graduated compression stockings (in patients without prophylaxis the incidence amounted to $20 \%$ ). However, only $48 \%$ of patients in this study were operated due to a brain tumor (and only some patients suffered from malignant brain tumors). Although this study revealed a decrease in VTE incidence, when graduated compression stockings as well as complex prophylaxis with graduated compression stockings combined with intermittent pneumatic compression were used, there was no statistically significant difference between groups, in which mechanical prophylaxis was applied. Therefore, further studies are required in order to evaluate the role and efficacy of graduated compression stockings in neurosurgical patients and to directly compare the effectiveness of IPC with graudated compression stocking application [169]. In the study conducted by Wautrecht et al. on a small group, none of the 18 neurosurgical patients (100\% of enrolled subjects suffered from a brain tumor), who received intermittent pneumatic compression combined with compression stockings developed DVT, whereas 2 of 5 patients, who used compression stockings only, developed deep venous thrombosis [170].

Recently, there is increased interest in other methods of mechanical prophylaxis such as electrical calf stimulation (ECF). The study conducted in order to assess the effectiveness of ECF in high-risk neurosurgical 
patients found that deep venous thrombosis incidence dropped from $18.7 \%$ to $4 \%$, including proximal deep vein thrombosis rate decrease from $8 \%$ to $2.7 \%$, and symptomatic DVT reduction from $2.7 \%$ to $0 \%$ [I $7 \mathrm{I}]$.

Pharmacological prophylaxis in patients at a high and very high risk of VTE, especially those combining pharmacological prophylaxis with mechanical methods, potentially reduces the thromboembolic complication incidence in other medical fields [14]. Due to characteristics of neurosurgical patients operated on account of oncological reasons and a potential neurosurgery as well as pharmacological prophylaxis related bleeding risk, this subject requires further studies also in the field of the cancer neurosurgical treatment. Meta-analysis of 4 randomized controlled clinical trials on pharmacological prophylaxis for thrombosis prevention in neurosurgery (three of them involving antithrombotic prophylaxis with low-molecular-weight heparin and one of them low doses of unfractionated heparin, with or without mechanical prophylaxis methods proved that DVT incidence dropped from $29 \%$ in controls to $16.1 \%$ in patients, who received pharmacological prophylaxis (proximal DVT incidence dropped from $12.5 \%$ to $6.25 \%$ ). Regarding the hemorrhagic complications, at the time, the risk of "major" bleedings increased from $2.5 \%$ to $3.1 \%$, and the overall bleeding incidence increased from $2.9 \%$ to $5.9 \%$ [I 72$]$.

The timing of the antithrombotic pharmacological prophylaxis administration plays an important role in neurosurgical patients. Due to the fact that most of the intracranial bleedings in neurosurgical patients occur within the first 12-24 hours after craniotomy, and half of thromboembolic events occur later (after the first week after surgery), in patients at a high risk of VTE, it is justified to start VTE pharmacological prophylaxis postoperatively (after obtaining proper hemostasis) [146, I60].

Dickinson et al. conducted a study on patients with brain tumors and attempted to compare effectiveness of antithrombotic prophylaxis in 3 groups of patients, who received intermittent pneumatic compression, $\mathrm{LMWH}$ (enoxaparin) and combination therapy with two of the aforementioned methods. In this study, $\mathrm{LMWH}$ was administered before surgery. The trial was discontinued due to a high bleeding rate in patients where pharmacological prophylaxis was administered before surgery (the hemorrhagic events occurred mostly in an early postoperative period and 3 patients required surgical reintervention). The authors suggest that patients receiving low-molecular-weight heparin should undergo intracranial procedures no sooner than after an appropriate time after the last dose of LMWH [ 173]. Agnelli and Nurmohamad evaluated effectiveness and safety of LMWH at prophylactic dose administered with the first 24 hours after surgery (LMWH + graduated compression stockings vs. LMWH) $[168,174]$. In the first trial, DVT and proximal DVT incidence amounted to $33 \%$ and $13 \%$ respectively in the group of patients, who used only graduated compression stockings in comparison to $17 \%$ and $5 \%$ in the group, who received combined prophylaxis [168]. In the second trial, the incidence amounted to $26 \%$ and $12 \%$ respectively in patients using only compression, and $19 \%$ and $7 \%$ for combination of mechanical and pharmacological prophylaxis (with LMWH prophylaxis started postoperatively).

Also in phlebography based studies, a drop in incidence of proximal deep venous thrombosis from $28.9 \%$ to $17.9 \%$ was observed in patients, who received combination prophylaxis (along with a decrease in proximal DVT rate from $12 \%$ to $5.7 \%$, and an increase in incidence of "major" bleeding complications from $2.0 \%$ in patients receiving graduated compression to $3.4 \%$ in patients, who additionally received LMWH) [168, 174].

Effectiveness and safety of unfractionated heparin administered at low doses for pharmacological prophylaxis in neurosurgical patients, including a substantial number of patients operated on account of a brain tumor, was also assessed. Unfortunately, the outcomes of these studies also raise doubts regarding especially the characteristics of the treated population. Cerrato et al. analyzed the effect of antithrombotic prophylaxis with low doses of unfractionated heparin (prophylaxis began before surgery) in a group of patients, $87 \%$ of whom were suffering from a brain tumor, and discovered a drop in incidence of asymptomatic VTE from $34 \%$ to $6 \%$ [175]. Constatini et al. using a similar VTE prophylaxis algorithm did not observe "major" bleedings, however, at the same time did not report a decrease in incidence of symptomatic DVT in comparison to placebo [ 176]. Two other studies comparing prophylactic administration of LMWH and LDUH combined with mechanical prophylaxis (63-93\% of patients in this group suffered from a brain tumor) did not find significant differences in incidence of "major" bleedings between the groups [177, I78].

The analysis performed by Collen et al. on 18 randomized clinical trials and 12 prospective trials on application of IPC, LMWH and low dose unfractionated heparin for thromboembolism prevention in neurosurgery confirms the effectiveness of both methods (mechanical prophylaxis — IPC and pharmacological prophylaxis - LMWH) [I $5 \mathrm{I}]$. Application of LMWH, as well as IPC, decreased the risk of DVT, simultaneously increasing the risk of minor bleedings, and increasing the incidence of the complex study end-point defined as "minor" bleeding occurrence and intracranial bleeding in the group of patients treated with LMWH [15I]. 
Meta-analysis conducted by Hamilton et al. comparing results of VTE prophylaxis in 1170 patients (6 randomized clinical trials on low dose unfractionated heparin or low-molecular-weight heparin administration in comparison to the controls not receiving pharmacological prophylaxis), who underwent neurosurgical operations within the skull, confirmed that prophylactic heparin doses reduce DVT incidence and, at the same time, increase the risk of intracranial bleeding [152]. Based on this analysis, pharmacological prophylaxis used in 1000 patients, who underwent craniotomy, will potentially prevent 91 venous thromboembolism events (including 35 proximal deep venous thrombosis or pulmonary embolism cases), and at the same time will put 7 patients at risk of intracranial bleeding, and 28 patients at risk of "minor" bleeding complications [152]. The systematic review based on the treatment results of 1932 patients, from which 1558 were operated on the account of a brain tumor should be also mentioned in the context of these guideline proposal [150]. The authors concluded that administration of mechanical prophylaxis before surgery and its continuation until discharge reduce the incidence of venous thromboembolism without an increase in bleeding risk. Administration of pharmacological prevention with LMWH further reduces VTE incidence and increases the risk for "major" bleeding complications [150]. Due to significant heterogenicity of analyzed populations, various prophylaxis regimens used as well as the differences in bleeding complication risk related to the type of procedure performed, there is a need for further research in order to define an optimal antithrombotic prevention method in patients undergoing neurosurgical oncological procedures.

\section{Guidelines \\ VTE prophylaxis in neurosurgical cancer patients}

\section{Guideline 3.3.I}

The risk for venous thromboembolism as well as for bleeding complications should be assessed individually for each patient undergoing neurosurgical oncological procedures [IA].

\section{Guideline 3.3.2}

Due to potential bleeding risks, patients undergoing intracranial oncological neurosurgery should receive mechanical prophylaxis for prevention of venous thromboembolism, most preferably by the means of intermittent pneumatic compression, in the perioperative and postoperative period [2C].

\section{Guideline 3.3.3}

In patients undergoing intracranial oncological neurosurgery related to high or very high risk of venous thromboembolism, who are not at high risk for bleeding, in the postoperative period the pharmacological thromboprophylaxis by the means of low doses of unfractionated heparin or low molecular heparin should be added to the mechanical methods of prophylaxis [2C].

\section{Guideline 3.3.4}

In patients undergoing intracranial oncological neurosurgery qualified for pharmacological antithrombotic prevention, the pharmacological prophylaxis should be started postoperatively, if proper hemostasis is achieved [2C]. The time, when pharmacological prophylaxis should begin must be assessed individually considering bleeding risk and local hemostasis [IC].

\section{Guideline 3.3.5}

Patients undergoing intracranial oncological neurosurgery should not undergo inferior vena cava filter placement for primary antithrombotic prevention [2C].

\subsection{VTE prophylaxis in surgical urological cancer patients}

It is often difficult to estimate surgery-related bleeding risk for the urinary tract. A limited number and quality of studies on this issue hinder elaboration of final guidelines on VTE prophylaxis in patients undergoing urologic oncological surgeries [14, 179]. Because of that fact, many up-to-date guidelines extrapolate results of the studies conducted on patients undergoing abdominal and pelvic surgery [14, 21 , 23, 30]. Lack of research of sufficient quality hinders elaboration of guidelines dedicated to anti-thrombotic prophylaxis in the particular urologic procedures. Hitherto, such guidelines were formulated only by the American Urological Association as the Best Practice Statement in 2008 [ 180]. Although, this document determines cancer as a significant VTE risk factor, the AUA statement applies to patients undergoing urological surgery because of various reasons, including cancer-unrelated ones [180].

The characteristics of urology itself, high percentage of endoscopic and laparoscopic procedures along with a high bleeding risk justify taking them into account in an elaboration of guidelines for antithrombotic prophylaxis and individual approach to each patient qualified to urologic oncological surgery.

In extensive and open urologic oncological surgeries within the lesser pelvis (prostatectomy, cystectomy), 
the VTE risk, when no prophylaxis is given, corresponds to the risk observed for extensive procedures in general surgery (VTE risk at 10-30\%, pulmonary embolism risk at $\mathrm{I}-10 \%)[14,179,18 \mathrm{I}-183]$. Symptomatic venous thromboembolism occurs on average in $1-5 \%$ of patients after extensive urologic surgeries within the pelvis [14]. This risk seems to be even higher in some extensive urologic intraabdominal oncological surgeries. Radical oncological cystectomy with ileal conduit urinary diversion is an example of such a procedure $[14,179,184]$. In the study published in 2015 based on retrospective analysis of 27,455 patients, who underwent extensive urologic oncological surgeries, symptomatic VTE was diagnosed in $2.93 \%$ of cases [185]. The highest incidence of symptomatic VTE within 30 days after surgery was observed in patients after radical oncological cystectomy and amounted to $5.5 \%$ (there were no data available regarding antithrombotic prophylaxis), whereas the incidence amounted to only $0.7 \%$ in patients, who underwent minimally invasive or partial nephrectomy due to cancer [185]. Similar data suggesting high percentage of VTE in patients undergoing radical cystectomy due to cancer can be found in other reports. Potretzke et al. detected symptomatic VTE in $8.3 \%$ of patients after radical oncological cystectomy [186]. VanDlac and Rosario estimated in two independent trials that the risk for symptomatic VTE in patients after radical cystectomy amounts to $6 \%$ [187, 189]. Based on treatment results of I58I patients after radical cystectomy performed due to urinary bladder cancer, James reported that VTE occurred in $10 \%$ of the cases within 90 days after surgery [189].

Most of the available data concerning VTE risk and antithrombotic prophylaxis in patients undergoing urologic cancer surgery reffers to patients after radical prostatectomy. According to the reports published in recent years, estimated risk of symptomatic VTE ranges from $0.8 \%$ to $6.2 \%$ in patients, who underwent open prostatectomy, whereas the risk of fatal pulmonary embolism amounts to $0.4-1.1 \%$ [190-199]. Dilioglugi et al. found that in the group of 472 patients after prostatectomy, I. I\% suffered from symptomatic pulmonary embolism and 1.3\% from DVT [198]. Likewise, Andriole and Catalona based on treatment results of I,000 patients after this kind of surgery estimated the VTE incidence at $2.6 \%$ and $2 \%$ respectively $[197,200]$. Hammond et al. analyzed 20,000 extensive oncological surgeries, including urological oncological surgery and found that symptomatic VTE occurred in I.8\% of patients after prostatectomy [20I]. In cases, where no prophylaxis was applied and thromboembolic complications were assessed by the means of imaging methods after prostatectomy, the risk seems to be significantly higher (16.8-32\%), which results from high percentage of asymptomatic deep venous thrombosis cases [203-204].

Aside from the presence of cancer, significant risk factors in patients undergoing urologic surgeries include: advanced age, extensive pelvic surgeries, extensive retroperitoneal lymphadenectomy, lithotomy position, obesity, and hormonal therapy (e.g. anti-androgen treatment), and, as in other medical fields, clinically significant concomitant disease presence [14, 205-208]. The presence of cancer also increases the risk for symptomatic VTE occurrence after upper urinary tract surgeries up to $I-5 \%[14,179,12,183]$. California Patient Discharge Data Set retrospective analysis estimated the incidence of symptomatic VTE at $2 \%$ after nephrectomy preformed because of malignancy [190]. Pettus et al. evaluated the VTE incidence in 2208 patients after partial or radical nephrectomy (only mechanical methods of VTE prophylaxis were used) and estimated that symptomatic VTE occurred in $1.5 \%$ of patients and pulmonary embolism in $0.9 \%$ [209]. In case of renal cancer, risk factors for VTE complications, aside from staging and the presence of metastases, include: the presence of concomitant diseases, long surgery duration, non-radical operation, cancer infiltration into the renal vein and/or inferior caval vein [2।0-2।2].

Because of the development of laparoscopic techniques, also in urology more and more procedures are performed by the means of minimally invasive surgery, such as robotic surgical systems. However, even these procedures, despite of significantly less severe surgical trauma and faster mobilization of the patient, are not free from thromboembolic complications. Incidence of VTE amounts to $0.13-4.8 \%$ of patients, who underwent urologic laparoscopic surgery, whereas incidence of pulmonary embolism is estimated at 0.08-1\% [2।3-220]. Chalmers et al. analyzed VTE incidence in 1486 patients after radical robotic prostatectomy and antithrombotic prophylaxis with intermittent pneumatic compression combined with low doses of unfractionated heparin or intermittent pneumatic compression prophylaxis only. In both groups the incidence of symptomatic VTE was comparable (I.0\% vs. $0.7 \%)$ [ $22 \mathrm{I}]$. The other authors also report relatively low incidence of symptomatic VTE $(0.5-0.6 \%)$ in laparoscopic or robotic prostatectomy [220, 222]. On the other hand, some reports suggest higher risk for such complications despite of antithrombotic prophylaxis administration in this clinical settings. Abel et al. found that within 30 days after radical robotic prostatectomy, VTE occurred in $1.8 \%$ of patients (despite of mechanical methods of antithrombotic prevention implementation as well as pharmacological prophylaxis with single heparin dose administered before surgery) [223]. The authors of this 
study indicate that surgery duration is also important in the context of an increased VTE risk [223].

Urologic endoscopic procedures (transurethral urological surgery) are also not free from thromboembolic complications, although the incidence of symptomatic VTE is significantly lower in these kind of the procedures (symptomatic VTE: 0. I-0.75\%; PE 0. I-0.84\%). The presence of cancer as well as other concomitant diseases may significantly increase the risk of DVT and $P E$ in patients, who undergo transurethral procedures such as transurethral electro-resection of the prostate as well as resection of bladder cancer [14, 182, 190, 224]. The analysis of extensive California Patient Discharge Data Set assessed symptomatic VTE incidence at $0.3-0.5 \%$ in patients, who underwent transurethral resection of prostate adenoma within 3 months after surgery. On the other hand, according to White et al. the VTE incidence in patients after e.g. percutaneous nephrostomy performed due to cancer amounted to $3.6 \%$ [190].

Clinical application of guidelines on antithrombotic prophylaxis, as well as progress in the surgical techniques resulting among others in the reduction of procedure duration, significantly decreased incidence of thromboembolic complications after extensive urologic surgeries [14, I79, 206]. On the other hand, application of minimally invasive techniques reduced incidence of thromboembolic complications but did not eliminate them entirely, whereas pulmonary embolism remained to be the most common nonsurgical cause of death in this group [14, 180]. Like in the other surgical specialties, assessment of VTE risk and bleeding risk is crucial for the proper qualification for antithrombotic prophylaxis $[14,180,225]$. Because of the fact that there are no studies referring to the particular clinical situations (the same type of surgery, same bleeding risk and VTE risk) of sufficient quality, individual approach and treatment in each patient is encouraged.

The number of prospective clinical trials on antithrombotic prophylaxis in patients undergoing urologic surgery, including cancer surgery, is limited. Kutnowski and Sebseri report that the DVT incidence decreased after administration of low doses of unfractionated heparin for VTE prophylaxis in patients undergoing urologic surgeries (from 36-58\% to 9-12\%) [226, 227]. Bigg et al. obtained similar results in the group of patients after open prostatectomy (PE: 0\% vs. I I\%) [228]; incidence of pulmonary embolism was significantly lower after prophylactic heparin administration. Vandendris used low doses of unfractionated heparin for prophylaxis in patients qualified for open prostatectomy and reported a drop in deep venous thrombosis incidence from $39.4 \%$ to $9.7 \%$ [229]. In a review of 7 prospective randomized clinical trials on pharmacological anthrombotic prevention, Collins et al. documented a significant drop in DVT incidence accompanied by a significant increase in the risk of bleeding in patients receiving low doses of unfractionated heparin for prophylaxis (incidence of clinically significant bleeding complications ranged from: $3.8 \%$ to $5.9 \%$ ) [230].

By far there are no prospective randomized clinical trials of sufficient quality focusing on low-molecular-weight heparin administration for antithrombotic prevention in urologic cancer patients [23I]. Studies on administration of LMWH for antithrombotic prophylaxis performed thus far in this group of patients are based on retrospective analyses or on prospective follow-up of the small patient groups. In the study conducted by Sawczuk on 38 patients qualified for elective urologic cancer surgery, dalteparin (2500 units s.c., prophylaxis began I-2 hours before surgery) along with intermittent pneumatic compression was used. Within 3-7 days of thromboembolism prophylaxis, there was no symptomatic VTE episode diagnosed and at the same time, no excessive bleeding was observed [232]. Koch assessed the effectiveness of enoxaparin administered an hour before surgery at the dose of $30 \mathrm{mg}$ (and next after 12 hours) in patients undergoing open prostatectomy and did not report symptomatic VTE events in the group receiving prophylaxis, whereas $3.3 \%$ in the controls, who used only compression means, presented with thromboembolic events [233]. In this study, postoperative bleedings (7.8\% vs. $0 \%$ ) and lymph collection in the pelvis were diagnosed more often in patients receiving pharmacological prevention [233]. Information on potential influence of pharmacological prophylaxis on incidence of lymph collection after pelvic lymphadenectomy is also available in the other studies [234-237]. Boncinelli et al. compared the effectiveness of treatment with nadroparin in the single daily dose of $0.3 \mathrm{~mL}$ with LDUH at the dose of $3 \times 5000 \mathrm{U}$ in 50 patients undergoing open prostatectomy in a prospective randomized clinical trial. In both groups neither symptomatic thromboembolic complications nor bleeding complications were observed [238].

Available studies also refer to postoperative antithrombotic prophylaxis as one of the VTE prevention methods [239, 240]. Nakumara used enoxaparin at the dose of $40 \mathrm{mg}$ (prophylaxis began 6-8 hours after surgery) in a group of 47 patients, who underwent open prostatectomy, and reported VTE incidence at $4 \%$ [239]. Grasso et al. retrospectively analyzed 500 patients after radical prostatectomy, who received hemodilution, compression stockings, and pharmacological prevention administered up to 24 hours after surgery and found only two VTE episodes as well as two bleeding complications that required surgical intervention [240]. As for now there are no prospective 
randomized trials on prophylaxis for thrombosis after transurethral oncological surgeries, whereas few available reports on VTE prevention mostly refer to the patients undergoing urological surgery due to other reasons. Retrospective analysis of 883 patients, who underwent transurethral radical prostatectomy (TURP) and used graduated compression stockings indicated that symptomatic pulmonary embolism occurred in $0.45 \%$ of the patients [24I]. In the @RISTOS study conducted on patients undergoing cancer urological surgery (mostly due to bladder and prostate carcinoma, $61 \%$ of whom underwent laparoscopic surgeries) symptomatic VTE was found in $0.87 \%$ of patients, while $71 \%$ of the patient population received prophylaxis during hospitalization, and in $32 \%$ of them prophylaxis was continued after discharge [242].

In endoscopic urologic surgeries as well as in open surgery, bleeding risk assessment is significant for the proper an safe thromboembolism prophylaxis implementation [225, 243]. In this context, in the patients with elevated bleeding risk mechanical prophylaxis methods, such as intermittent pneumatic compression are of special interest. According to the performed studies, intermittent pneumatic compression in patients undergoing open urologic surgeries causes a reduction in VTE incidence [244]. Koya found VTE incidents only in $0.21 \%$ of $\mathrm{I}, 364$ patients undergoing radical prostatectomy, who used early mobilization and intermittent pneumatic compression for thromboprophylaxis [245]. On the other hand Cisek et al. suggest that application of intermittent pneumatic compression in high-risk patients does not decrease the total VTE risk in this population, however does significantly delay thrombosis event occurrence (the average time for VTE diagnosis in this study amounted $3020 \pm 2$ days vs. II \pm 5 days after surgery) [246]. In this group of patients (patients at high risk and very high risk for VTE), it seems reasonable to use pharmacological prophylaxis or combination treatment instead of only mechanical methods of VTE prophylaxis [14, 180].

Alike in general surgery, combination of mechanical methods with pharmacological prevention reduces VTE risk, and it is more clinically effective than any of those methods used alone [88, 247]. By far, few studies on urological patients (including two randomized trials), did not prove the advantage of intermittent pneumatic compression over LDUH administration in this group of patients [248, 249]. Montgomery et al. conducted retrospective analysis of urological laparoscopic surgeries and compared effects of thromboprophylaxis with LDUH or intermittent pneumatic compression. The analyzed population included patients qualified for laparoscopic urologic surgeries (including 217 patients, who underwent nephrectomy). There were no signi- ficant differences in VTE incidence between groups, however patients who received pharmacological prevention showed bleeding complications more often (bleeding incidence $9.3 \%$ vs. $3.5 \%$; major bleedings $7.0 \%$ vs. $2.9 \%$ ) [250]. In the aforementioned study conducted on 5,95 I patients undergoing either laparoscopic prostatectomy or robotic prostatectomy, $67 \%$ of the subjects received heparin in the perioperative period. In spite of a low VTE rate $(0.5 \%)$ and pulmonary embolism rate $(0.2 \%)$ perioperative administration of $\mathrm{LMWH}$ was related to higher blood loss, longer hospitalization period, higher transfusion rate, and higher percentage of reoperations [219].

Due to limited invasiveness and often short duration of gradually more commonly performed laparoscopic surgeries (e.g. in the field of general surgery), up-to-date guidelines on laparoscopic surgeries do not encourage routine administration of pharmacological prophylaxis, permitting for early mobilization and mechanical methods implementation [14,92, 180]. Other risk factors such as prolonged laparoscopic surgery, lesser pelvis surgery and cancer increase the risk, and according to the individual VTE and bleeding risk assessment, thus justifying the administration of prevention methods (including pharmacological prophylaxis).

Like in other disciplines, the question of how long prophylaxis should last remains open. Based on extrapolation of guidelines referring to surgical patients, it is reasonable to administer primarily prolonged thromboprophylaxis with low-molecular-weight heparin to the patient undergoing extensive surgery of the abdomen and pelvis, including cancer surgery [14]. Alberts et al. in the study referring to the analysis performed by the National Surgical Quality Improvement Program in the USA between 2002 and 2012 emphasize that, up to $82.6 \%$ of VTE events after radical prostatectomy were diagnosed after discharge [25I]. Leibovitch et al. concluded in their study that 7 of 9 cases of DVT diagnosed after radical retropubic prostatectomy occurred after discharge [192]. VanDlac et al. reported that in a group of I,307 patients after radical cystectomy, $55 \%$ of VTE events were diagnosed after discharge [252]. The study performed by Kukreja et al., is one of the few works on appropriate antithrombotic prophylaxis duration in urology [253]. The authors of this study compared outcomes of thromboprophylaxis in patients undergoing urologic cancer surgery in the context of prophylaxis duration (prophylaxis in the hospital vs prophylaxis for 28 days after surgery). In the group receiving prolonged prevention VTE occurred in $7 \%$ of cases, whereas in $17 \%$ of patients, who received treatment in the hospital VTE was diagnosed; there were no differences in the bleeding rates between the groups [253]. 
The authors of guidelines are aware of the fact that the quality and number of reports on thromboprophylaxis in patients undergoing urologic cancer surgeries are limited, and therefore suggest an individual VTE risk as well as risk of bleeding assessment. At the same time, due to low quality of most of the guidelines, the authors emphasize the need for further studies and potential modifications implemented based on results of these studies as well as for an individual approach to risk assessment for venous thromboembolism and bleeding in each case.

\section{Guidelines \\ VTE prophylaxis in urological patients operated due to cancer}

\section{Guideline 3.4.I}

The risk of venous thromboembolism and of bleeding complications should be assessed individually for each patient undergoing urologic surgery due to cancer [IA].

\section{Guideline 3.4.2}

In patients undergoing major urological surgery due to cancer and in those undergoing other urological procedures, who are at high risk of venous thromboembolism, it is recommended to consider the use of thromboprophylaxis based on LDUH [IB] or LMWH [IC], if the risk of bleeding do not significantly outstands potential benefits associated with the use of pharmacoprophylaxis. Due to the limited availability of research and the specificity of the treated population, the optimal moment of starting pharmacological prophylaxis in these patients has not been finaly defined and therefore should be based on individual evaluation of the benefits and risks of this type of prophylaxis [2C]. In case of a significant bleeding risk in the perioperative period, it is suggested to use mechanical methods of VTE prevention (most preferably intermittent pneumatic compression) [IC].

\section{Guideline 3.4.3}

In cancer patients with moderate VTE risk undergoing other surgeries than major ones, it is recommended to decide about the method and the time for administration of thromboprophylaxis according to present risk assessment for VTE and bleeding complications [2C].

\section{Guideline 3.4.4}

In patients undergoing urologic surgery due to cancer at high risk of venous thromboembolism and bleeding complications, or in patients with contraindications for pharmacological prophylaxis, it is suggested to use mechanical prophylaxis, (most preferably intermittent pneumatic compression), at least until the bleeding risk decreases and administration of pharmacological prophylaxis becomes possible [2C].

\section{Guideline 3.4.5}

It is suggested that in cancer patients undergoing major urologic surgeries, qualified for pharmacological prophylaxis due to high or very high risk of venous thromboembolism, pharmacological prevention should be supported with mechanical methods (most preferably intermittent pneumatic compression) [2C].

\section{Guideline 3.4.6}

In patients undergoing major urologic surgeries in the abdominal cavity and/or pelvis, who are not at high risk of serious bleeding complications it is suggested to prolong pharmacological prophylaxis (4 weeks) with low-molecular-weight heparin [2C]. In the other cases, the decision regarding prolongation of prophylaxis should be made individually based on benefits and risk of such treatment [2C].

\section{Guideline 3.4.7}

In laparoscopic cancer surgery it is suggested to assess the risk of venous thromboembolism individually [I] as well as to use the same rules of thromboprophylaxis as in patients operated by the means of laparotomy performed due to cancer [2C].

\section{Guideline 3.4.8}

In patients undergoing transurethral and percutaneous endoscopic surgeries due to cancer it is suggested to assess the risk of venous thromboembolism and the risk of bleeding complications individually as well as to decide on prophylaxis administration based on evaluation of benefits and risks of such treatment [2C]. The decision on prophylaxis administration as well as the chosen prevention method, and the right time for its administration should be based on characteristics of the particular procedure and bleeding risk assessed individually in each case [2C]. In the case of high risk of bleeding, in the first place, early patient mobilization as well as mechanical prophylaxis should be used [2C], and pharmacological prophylaxis should be added, when hemostasis is satisfactory [2C].

\section{Chapter 4. Prevention of venous thromboembolism in cancer patients ineligible for surgical treatment and treated in hospital settings}

Cancer itself is an important risk factor for VTE not only in surgical patients, but also in those hospitalized on surgical and non-surgical wards and treated conservatively $[4,9,23,28,32,33,254]$. Because of the tumor, concomitant risk factors of VTE and factors relating to both patient's condition and treatment itself, most cancer patients admitted to the hospital will require thromboprophylaxis adequate to the risk $[15,32,33,36,38,254]$. Despite the 
Table 2. The risk factors for venous thromboembolism, taking into account the characteristics of the cancer patient's population [modified according to 15,28 ]

\begin{tabular}{|c|c|}
\hline Category & Risk factor \\
\hline $\begin{array}{l}\text { Risk factors depend on the patient } \\
\text { and comorbidity }\end{array}$ & $\begin{array}{l}\text { Age (> 40) } \\
\text { A positive family history } \\
\text { Obesity } \\
\text { Trauma (in particular polytrauma, pelvic fractures, fractures of long bones } \\
\text { of the lower limb) } \\
\text { Cerebrovascular events with paresis or mobility restriction } \\
\text { Sepsis } \\
\text { Acute infection } \\
\text { Heart failure NYHA III and IV } \\
\text { A history of myocardial infarction } \\
\text { Respiratory failure (especially exacerbation) } \\
\text { Autoimmune diseases } \\
\text { Nephrotic syndrome } \\
\text { Myeloproliferative syndrome } \\
\text { Paroxysmal nocturnal hemoglobinuria } \\
\text { Vein compression } \\
\text { Pregnancy and postpartum } \\
\text { Vein varicose in lower limbs } \\
\text { History of venous thromboembolism } \\
\text { Thrombophilia } \\
\text { Long-term immobilization (in hospital, at home, or due to traveling) }\end{array}$ \\
\hline $\begin{array}{l}\text { Risk factors depend on the type } \\
\text { and stage of cancer }\end{array}$ & $\begin{array}{l}\text { Tumor location } \\
\text { Staging (risk increases along with staging) } \\
\text { Type of cancer (pathological result) } \\
\text { Time after diagnosis (increase in the first } 3-6 \text { months and in advanced cases) }\end{array}$ \\
\hline Risk factors depend on therapy & $\begin{array}{l}\text { Surgical treatment } \\
\text { Prolonged postoperative immobilization } \\
\text { Chemotherapy } \\
\text { Hormone therapy, HRT, use of selective estrogen receptor modulators } \\
\text { Radiotherapy } \\
\text { Transfusions of packed red blood cells, plasma } \\
\text { Administration of erythropoesis stimulating factors } \\
\text { Administration of angiogenesis inhibitors } \\
\text { Central catheters, ports } \\
\text { Leukocytosis (above } 1 \mathrm{I} \times 109 / \mathrm{L}) \\
\text { Anemia-hemoglobin }<100 \mathrm{~g} / \mathrm{L}\end{array}$ \\
\hline
\end{tabular}

lack of qualifications for surgical treatment, cancer patients receiving conservative treatment in the hospital (also in surgical wards) are also at higher risk of VTE [15, 32, 36, 254] (Table 2).

Cancer treatment, particularly chemotherapy and combination therapy including cytostatics, angiogenesis inhibitors or drugs that affect the hormonal status of the patient are considered to be a potential risk factor for VTE in hospitalized patients especially, when the patient's mobility is limited in the hospital settings [32, 33, 36-38]. Nevertheless, the issue of routine thromboprophylaxis in hospitalized patients, who are undergoing diagnostics for cancer remains open. In these cases, the decision to implement pharmacological prophylaxis should be made, considering an individual assessment of the risk of VTE and the risk of bleeding complications associated with the treatment.

Thus far, no prospective clinical trials were performed on VTE prophylaxis for VTE specifically in the group of hospitalized cancer patients receiving conservative treatment. However, these patients participated in the study on efficacy of pharmacological thromboprophylaxis in the group with medical patients, who were immobilized in hospital with acute medical ilness as a part of the analyzed population (5-15\%) [255-257]. The aforementioned studies dedicated to the medical patients proved the advantage of active pharmacological prophylaxis with low-molecular-weight heparin, low doses of unfractionated heparin, and fondaparinux over placebo [255-257]. A number of research on efficacy 
of low-molecular-weight heparin and unfractionated heparin in patients admitted to the hospital on account of acute internal disease showed that $\mathrm{LMWH}$ presents at least comparable effectiveness [258-264].

Based on the results of the aforementioned studies, most guidelines available thus far recommend administration of thromboprophylaxis with low-molecular-weight heparin, unfractionated heparin, or fondaparinux in hospitalized patients receiving conservative treatment ("medical patients"), including those suffering from cancer, who are immobilized in hospital due to an acute medical illness [15, 28, 254].

As mentioned before, there are still no studies on hospitalized cancer patients receiving conservative treatment in hospital. Although most of the hospitalized cancer patients, who do not receive surgical treatment require VTE prophylaxis due to concomitant risk factors, the decision regarding pharmacological prophylaxis administration in patients admitted to hospital and undergoing diagnostic procedures, as well as the ones receiving short-term chemotherapy infusions should be made individually. Each time it should be based on an individual assessment of risk of VTE as well as the risk of pharmacological prophylaxis [4, 9]. Similar controversies apply to patients with a central vein catheter — despite the fact that earlier reports suggest that it is reasonable to administer thromboprophylaxis in this group of patients with a central catheter, recent reports do not confirm that the routine use of pharmacological prophylaxis of VTE is justified in these individuals [15, 32, 33, 265].

In everyday practice low-molecular-weight heparin remains the most commonly administered drug in patients with potential indications for pharmacological thromboprophylaxis in hospital. The authors of these guidelines recommend to use low-molecular-weight heparins according to the manufacturer's recommendations. Thus far there are no reports confirming that it is possible to use these new anticoagulants (factor $\mathrm{Xa}$ inhibitors and factor II inhibitors) for thromboprophylaxis in cancer patients receiving conservative treatment. Until there are trials correctly projected and performed, it is not recommended to use them for primary thromboprophylaxis in cancer patients.

\section{Guidelines \\ The prevention of venous thromboembolism in cancer patients receiving conservative treatment in hospital settings}

\section{Guideline 4.}

All cancer patients admitted to the hospital for diagnostics and/or treatment should undergo individual risk assessment for VTE considering risk factors related to cancer and the therapy, as well as those related to the patient's present condition and comorbidities [IA].

\section{Guideline 4.2}

It is recommended to use pharmacological thromboprophylaxis with low-molecular-weight heparin or low doses of unfractionated heparin in hospitalized cancer patients who are immobilized because of an acute medical ilness [IA].

\section{Guideline 4.3}

It is recommended to use thromboprophylaxis with low-molecular-weight heparin or low doses of unfractionated heparin in hospitalized cancer patients with limited mobility and/or the presence of other VTE risk factors, unless there are contraindications to pharmacological prophylaxis or high risk of bleeding [IB].

\section{Guideline 4.4}

It is suggested to consider the use of thromboprophylaxis with low-molecular-weight heparin or low doses of unfractionated heparin in hospitalized patients with an active malignancy, unless there are contraindications to pharmacoprophylaxis or high risk of bleeding complications [2C].

\section{Guideline 4.5}

It is suggested to use mechanical methods of VTE prevention (most preferably intermittent pneumatic compression) in hospitalized patients with active cancer and indications for prevention of VTE, in the case of active bleeding or a high risk of bleeding complications, at least, until the bleeding risk decreases and administration of pharmacological prophylaxis becomes possible [2C].

\section{Guideline 4.6}

Routine pharmacological thromboprophylaxis is not recommended in patients with central venous catheters [IC].

\section{Chapter 5. Post-discharge treatment of patients suffering from malignancy - thromboprophylaxis in patients with cancer treated in an outpatient settings}

In the patients discharged after cancer surgery appropriate duration of thromboprophylaxis should be based on both: the type of performed surgery as well as on VTE risk factors presented in each case. Guidelines on postoperative prophylaxis were presented in the previous section concerning surgical patients (guidelines 2. 1-2.8). Aside surgery, risk factors for VTE including cancer treatment such as chemotherapy, hormone ther- 
apy, and combination therapy [32, 33, 38, 260, 270], type of the tumor and staging are also important [267, 268].

Chemotherapy used for cancer treatment may increase VTE risk through many mechanisms, which lead, among others, to damaging or activation of endothelial cells, platelet activation, or reduction of the level of natural inhibitors of coagulation $[269,270]$. Angiogenesis inhibitors, steroids and drugs affecting the patient's endocrine system also have potential influence on hemostasis disorders and hypercoagulability [27I-273].

Chemotherapy in hospitalized patients, immobility, and other potential risk factors for VTE justify the consideration of thromboprophylaxis in most patients, who are admitted to hospital [9, 15, 254].

Despite the theoretical background as well as the fact that chemotherapy is believed to be a risk factor for VTE, thus far no prospective randomized trials were performed on efficacy of pharmacological prophylaxis in hospitalized patients, who receive chemotherapy. Due to the fact that populations of the patients receiving cancer treatment are inhomogeneous, both from the standpoint of the type, stage of the tumor and therapeutic methods used, it is difficult to estimate the value of predictive factors of VTE in patients treated with chemotherapy. At the same time, available studies refer to the fact that some patients receiving cancer treatment are at higher risk of VTE $[274,275]$. To evaluate this risk, the model of the VTE risk assessment based on the observation of patients undergoing chemotherapy in an outpatient setting was proposed by Khorana and co-workers (Table 3) [274].

It was suggested to support this model in subsequent studies with D-dimer test and soluble P-selectin assess- ment. This increases sensitivity as well as the specificity of this scale [275].

While there is still no evidence to support the routine thromboprophylaxis in all patients receiving chemotherapy in outpatient setings, according to the performed studies there is evidence suggesting that pharmacological prophylaxis may be beneficial in at least some patients receiving this type of cancer treatment $[276,277]$. This applies mostly to the patients with solid tumors, especially the ones with locally-advanced or metastatic pancreatic cancer as well as locally-advanced lung cancer and metastatic lung cancer, where there are no contradictions and bleeding risk remains low [276].

The increased risk of thromboembolic complications in cancer patients may be related not only to the type and stage of cancer, but also to the systemic therapy that the patient received. The studies on administration of thalidomide and lenalidomide in patients with multiple myeloma, which suggest that the rate of thromboembolic complication is high in combination therapy with any of these drugs along with steroids and/ lor chemotherapy serves as an example [278-28I]. It is suggested that patients treated according to this plan should receive pharmacological VTE prophylaxis $[9,19$, 254]. Thromboprophylaxis may also be beneficial in patients receiving chemotherapy due to other indications, especially those, who have different risk factors such as chronic immobilization, history of venous thromboembolism or other comorbidities or conditions that increase the risk of VTE (Chapter 4, Table 2).

Although in outpatients receiving chemotherapy, pharmacological prophylaxis is still not recommended

Table 3. Risk assessment scale for venous thromboembolis in patients with cancer undergoing chemotherapy in out-patient settings [according to 274]

\begin{tabular}{|c|c|c|}
\hline Parameter of VTE & Odds ratio $(95 \% \mathrm{Cl})$ & Spot risk of VTE \\
\hline $\begin{array}{l}\text { Tumor location } \\
\text { - stomach, pancreas } \\
\text { - lung, lymphoma, gynecological, urinary bladder, } \\
\text { testicular } \\
\text { - breast, colon and rectum, head and neck } \\
\text { Platelet count before chemotherapy }>350 \times 109 / \mathrm{L} \\
\text { Hemoglobin level }<10 \mathrm{~g} / \mathrm{dL} \text { or administration of } \\
\text { erythropoiesis stimulating agents } \\
\text { Leukocyte count before chemotherapy }>11 \times 109 / \mathrm{L} \\
\text { BMI } \geq 35 \mathrm{~kg} / \mathrm{m}^{2}\end{array}$ & $\begin{array}{l}4.3(1.2-15.6) \\
1.5(0.9-2.7) \\
1.0 \text { (baseline) } \\
1.8(1.1-3.2) \\
2.4(1.3-4.2) \\
2.2(1.2-4) \\
2.5(1.3-4.7)\end{array}$ & $\begin{array}{l}2 \\
1 \\
1 \\
1 \\
1 \\
1 \\
1\end{array}$ \\
\hline Number of points & Risk category & The risk of VTE \\
\hline 0 & Low & $0.8 \%$ \\
\hline 1.2 & Intermediate & $1.80 \%$ \\
\hline$\geq 3$ & High & $7.1 \%$ \\
\hline
\end{tabular}

95\% Cl - 95\% confidence interval; BMI — body mass index 
as a routine procedure, in this very group of patients many prospective randomized clinical trials on pharmacological thromboprophylaxis in medical oncological patients were performed [277, 282-288]. The analysis of the results of these studies showed that the prevention of VTE with prophylactic doses of low-molecular-weight heparin was beneficial for at least some outpatients receiving chemotherapy, but at the same time indicates that there is a potential risk of bleeding complications in this patient group [278, 288, 289]. These findings as well as the still limited number of studies on this issue promotes an individual approach to the treatment and individual assessment of benefits, as well as the risks of thromboprophylaxis in these patients. Ben-Aharon et al. evaluated the results of I I prospective clinical trials conducted on 6,942 patients receiving chemotherapy in outpatient settings, who received primary pharmacological thromboprophylaxis. This analysis proved a significant reduction in the incidence of VTE in the entire evaluated population (this was especially visible in patients suffering from lung cancer and pancreatic cancer), whereas there was no increase in incidence of major bleedings [17]. Meta-analysis performed by Che et al., brought similar conclusions in terms of efficacy of prophylaxis. The authors proved that pharmacological prophylaxis with low-molecular-heparin is beneficial, but at the same time increases the risk of bleeding complications in outpatients undergoing chemotherapy [289]. At this point, it must be mentioned, that the results of each of the published studies significantly differ with respect to the type and the stage of tumors, cancer treatment as well as the obtained results, that is to say the reduction of thromboembolic complications and the incidence of bleeding complications. The example of that issue may be the effect of thromboprophylaxis on reduction of the incidence of VTE in outpatients treated for lung cancer and pancreatic cancer, whereas the thromboprophylaxis has no influence on incidence of VTE in advanced breast cancer [283, 284, 286].

The analysis conducted by Cochrane on prospective clinical trials focusing on prophylaxis administration of oral anticoagulants in outpatients suffering from cancer proved the pharmacological thromboprophylaxis reduced the risk of VTE [290]. The authors, however, emphasize that the potential risk of bleeding complications should be taken into account, when the decision is made to administer such treatment. Similar conclusions were reached by $\mathrm{Di}$ Niso et al. based on randomized clinical trial on thromboprophylaxis in outpatients receiving chemotherapy [288].

Limited clinical data refers to prolonged thromboprophylaxis in non-surgical patients (medical patients).
In patients undergoing major surgery of the abdomen and pelvis, based on studies, it is justified to extend pharmacoprophylaxis up, whereas this was not confirmed in medical patients admitted to hospital on account of acute medical illness [29I]. The EXCLAIM study aiming to assess the efficacy and safety of pharmacological prophylaxis prolonged up to 4 weeks with low-molecular-weight heparin (in comparison to the standard prophylaxis duration) in medical patients, detected statistically significant reduction in VTE incidence accompanied by statistically significantly higher risk of major bleedings [29l]. It should be emphasized that cancer patients enrolled into the study constituted only a small group of analyzed patients, therefore thus far there are still no trials dedicated to the proper duration of thromboprophylaxis in cancer patients receiving conservative treatment. In this situation, as has been mentioned before, it is justified to assess the risk of VTE individually as well as benefits and risks of pharmacological prophylaxis in the patient group.

\section{Guidelines \\ Post-discharge treatment of cancer patients - thromboprophylaxis in patients with cancer treated in an outpatient setting}

\section{Guideline 5.I}

Each discharge patient should be assessed on the present VTE risk [IA].

\section{Guideline 5.2}

It is not recommended to use routine pharmacological thromboprophylaxis after discharge in all cancer patients receiving conservative treatment and receiving thromboprophylaxis during hospital stay. The decision to prolong prophylaxis in discharged patients should result from the individual risk assessment for VTE, as well as evaluation of the benefits and risks of pharmacological thromboprophylaxis [2B].

\section{Guideline 5.3}

Routine pharmacological thromboprophylaxis is not recommended in all patients receiving outpatient chemotherapy [IB]. In case of significant VTE risk, the indications for thromboprophylaxis in patients receiving chemotherapy in an outpatient setting should be determined individually based on evaluation of benefits and risks arising from prophylaxis [2B].

\section{Guideline 5.4}

It is suggested to consider the use of pharmacological thromboprophylaxis in patients with locally advanced or metastatic pancreatic cancer [IB] or lung 
cancer [2B] treated with chemotherapy when the risk of bleeding is low and there are no contraindications.

\section{Guideline 5.5}

In patients with multiple myeloma receiving thalidomide or lenalidomide along with chemotherapy and/or dexamethasone it is suggested to implement pharmacological thromboprophylaxis with aspirin or LMWH in low-risk patients or LMWH in high-risk patients [2C].

\section{References}

I. Guyatt GH, Oxman AD, Kunz R et al (2008) Rating quality of evidence of and strength of recommandations. BMJ; 336: |049-105|.

2. Guyatt $\mathrm{GH}$, Oxman $A D$, Vist GE et al (2008) GRADE: an emerging consensus on rating quality of evidence and strength of recommendations. BMj; 336: 924-926.

3. Guyatt GH, Norris SL, Schulman S et al (2012) Methodology for the development of antithrombotic therapy and prevention of thrombosis guidelines: Antithrombotic Therapy and Prevention of Thrombosis, 9th ed: American College of Chest Physicians Evidence-Based Clinical Practice Guidelines. Chest; I4I (2 Suppl): 53S-70S.

4. Farge D, Debourdeau P, Beckers $M$ et al (2013) International clinical practice guidelines for the treatment and prophylaxis of venous thromboembolism in patients with cancer. J Thromb Haemost; I I: 56-70.

5. Debourdeau P, Farge D, Beckers $M$ et al (2013) International clinical practice guidelines for the treatment and prophylaxis of thrombosis associated with central venous catheters in patients with cancer. J Thromb Haemost; I I: 7I-80.

6. Lyman GH, Khorana AA, Falanga A et al (2007) American Society of Clinical OncologyAmerican Society of Clinical Oncology guideline: recommendations for venous thromboembolism prophylaxis and treatment in patients with cancer. J Clin Oncol; 25: 5490-5505.

7. Lyman GH, Kuderer NM; American Society of Clinical Oncology (2010) Prevention and treatment of venous thromboembolism among patients with cancer: the American Society of Clinical Oncology Guidelines. Thromb Res; 125 Suppl 2: SI20-SI 27.

8. Lyman GH, Khorana AA, Kuderer NM et al (2013) American Society of Clinical Oncology Clinical Practice. Venous thromboembolism prophylaxis and treatment in patients with cancer: American Society of Clinical Oncology clinical practice guideline update. J Clin Oncol; 31: 2189-2204.

9. Lyman GH, Bohlke K, Khorana AA et al (2015) Venous Thromboembolism Prophylaxis and Treatment in Patients With Cancer: American Society of Clinical Oncology Clinical Practice Guideline Update 2014. J Clin Oncol; 33: 654-656.

10. Mandalà M, Falanga A, Roila F (20I I) ESMO Guidelines Working Group Management of venous thromboembolism (VTE) in cancer patients: ESMO Clinical Practice Guidelines. Ann Oncol; 22 Suppl 6: 85-92.

II. Streiff MB, National Comprehensive Cancer Center Network (2010) The National Comprehensive Cancer Center Network (NCCN) guidelines on the management of venous thromboembolism in cancer patients. Thromb Res; 125 (Suppl 2): SI28-SI33.
12. Streiff MB, Bockenstedt PL, Cataland SR et al (2013) National comprehensive cancer network. Venous thromboembolic disease. J Natl Compr Canc Netw; I I: I402-1429.

13. Kahn SR, Lim W, Dunn AS et al (2012) Prevention of VTE in nonsurgical patients: Antithrombotic Therapy and Prevention of Thrombosis, 9th ed: American College of Chest Physicians Evidence-Based Clinical Practice Guidelines. Chest; 14 I (2 Suppl): el 95S-e226S.

14. Gould MK, Garcia DA, Wren SM et al (2012) Prevention of VTE in nonorthopedic surgical patients: Antithrombotic Therapy and Prevention of Thrombosis, 9th ed: American College of Chest Physicians Evidence-Based Clinical Practice Guidelines. Chest; I4I (2 Suppl): e227S-277S.

15. Zawilska K, Bała MM, Błędowski P et al (2012) [Polish guidelines for the prevention and treatment of venous thromboembolism. 2012 update]. Pol Arch Med Wewn; I 22 Suppl 2: 3-74.

16. Tomkowski W, Zawilska K, Chęciński P et al. (201 I) Profilaktyka i leczenie żylnej choroby zakrzepowo-zatorowej: „Konsensus polski" - aktualizacja 20II. Acta Angiol; 17 Suplement A.

17. Fijałkowska A, Szawłowski A, Wojtukiewicz M, Zawilska K (2008) Rekomendacje Polskiego Towarzystwa Chirurgii Onkologicznej: Profilaktyka i przeciwzakrzepowe leczenie u pacjentów z nowotworami złośliwymi. Nowotwory; I: 78-8I.

18. Mandalà M, Falanga A, Piccioli A et al (2006) Venous thromboembolism and cancer: guidelines of the Italian Association of Medical Oncology (AIOM). Crit Rev Oncol Hematol; 59: 194-204.

19. Farge $D$, Bosquet L, Kassab-Chahmi D et al (2010) 2008 French national guidelines for the treatment of venous thromboembolism in patients with cancer: report from the working group. Crit Rev Oncol Hematol; 73: 3I-46.

20. Debourdeau P, Kassab Chahmi D, Le Gal G et al (2009) 2008 SOR guidelines for the prevention and treatment of thrombosis associated with central venous catheters in patients with cancer: report from the working group. Ann Oncol; 20: |459-7|.

21. NICE guidance: Venous thromboembolism: reducing the risk: reducing the risk of venous thromboembolism (deep vein thrombosis and pulmonary embolism) in patients admitted to hospital [CG92]. https://www.nice.org.uk/guidance/cg92.

22. Konstantinides SV, Torbicki A, Agnelli G et al (2014) 2014 ESC guidelines on the diagnosis and management of acute pulmonary embolism. Eur Heart J; 35: 3033-3069.

23. Nicolaides AN, Fareed J, Kakkar AK et al (2013) Prevention and treatment of venous thromboembolism - International Consensus Statement. Int Angiol; 32: I I I-260.

24. Di Nisio M, Lee AYY, Carrier M, Liebman HA, Khorana AA, and for the Subcommittee on Hemostasis and Malignancy (2015) Diagnosis and treatment of the incidental venous thrombosis in cancer patients: guidance fro the SSC of the ISTH. J Thromb Haemost; 13:880-883.

25. Khorana AA, Otten H-M, Zwicker Jl et al (2014) Prevention of Venous Thromboembolism in Cancer Outpatients: Guidance from the SSC of the ISTH. J Throm Haemost; 12: 1928-1931.

26. Di Nisio M, Carrier M, Lyman GH, Khorana AA and for the Subcommittee on Haemostasis and Malignancy (2014) Prevention of venous thromboembolism in hospitalized medical cancer patients: guidance from the SSC of the ISTH. J Throm Haemost; 12: 1746-1749.

27. Zwicker JI, Connolly G, Carrier M, Kamphuisen PW, Lee AYY (2014) Catheter-associated deep vein thrombosis of the upper 
extremity in cancer patients: guidance from the SSC of the ISTH. J Throm Haemost; 12: 796-800.

28. Easaw JC, Shea-Budgell MA, Wu CMJ et al (2015) Canadian consensus recommendationson the management of venous thromboembolism in patients with cancer. Part I: prophylaxis. Curr Oncol; 22: 133-143.

29. Easaw JC, Shea-Budgell MA, Wu CMJ et al (2015) Canadian consensus recommendations on the management of venous thromboembolism in patients with cancer. Part 2: treatment. Curr Oncol; 22: 144-155.

30. Streiff MB, Holmstrom B, Ashrani A et al (2015) Cancer-Associated Venous Thromboembolic Disease, Version I.2015. J Natl Compr Canc Netw; I3: 1079-1095.

31. Watson HG, Keeling DM, Laffan M, Tait RC, Makris M; British Committee for Standards in Haematology (2015) Guideline on aspects of cancer-related venous thrombosis. $\mathrm{Br} J$ Haematol; 170: 640-648.

32. Elyamany G, Alzahrani AM, Bukhary E (2014) Cancer-associated thrombosis: an overview. Clin Med Insights Oncol; 8: 129-137.

33. Akl EA, Muti P, Schünemann HJ (2008) Anticoagulation in patients with cancer: an overview of reviews. Pol Arch Med Wewn; II8: 183-193.

34. Kakkar W, Howe CT, Nicolaides AN et al (1970) Deep vein thrombosis of the leg. Is there a "high risk" group? Am J Surg; 120: 527.

35. Rickles FR, Levine M, Edwards RL (1992) Hemostatic alterations in cancer patients. Cancer Metastasis Rev; II: 237.

36. Heit JA (2015) Epidemiology of venous thromboembolism. Nat Rev Cardiol; 12: 464-474.

37. Cushman M (2007) Epidemiology and risk factors for venous thrombosis. Semin Hematol; 44: 62-69.

38. Wun T, White RH (2009) Venous thromboembolism (VTE) in patients with cancer: epidemiology and risk factors. Cancer Invest; 27 (Suppl I): 63-74.

39. Pellino G, Sciaudone G, Candilio G, De Fatico GS, Canonico S, Selvaggi $F(2015)$ Predictors of Venous Thromboembolism after Colorectal Surgery in a Single Unit. Acta Chir Belg; I 15: 288-292.

40. Kucher N, Spirk D, Baumgartner I et al (2010) Lack of prophylaxis before the onset of acute venous thromboembolism among hospitalized cancer patients: the SWlss Venous ThromboEmbolism Registry (SWIVTER). Ann Oncol; 21: 931.

4I. Lyman GH (2009) Thromboprophylaxis with low-molecular-weight heparin in medical patients with cancer. Cancer; 115 : 5637.

42. Agnelli G, Caprini JA (2007) The prophylaxis of venous thrombosis in patients with cancer undergoing major abdominal surgery: emerging options. J Surg Oncol; 96: 265.

43. Heit JA, Silverstein MD, Mohr DN et al (2000) Risk factors for deep vein thrombosis and pulmonary embolism: a population-based case-control study. Arch Intern Med; 160: 809-8I5.

44. Nijziel MR, van Oerle R, Hillen HF et al (2006) From Trousseau to angiogenesis: the link between the haemostatic system and cancer. Neth J Med; 64: 403-4I0.

45. Caprini JA, Arcelus JI, Hasty JH, Tamhane AC, Fabrega F (|99|) Clinical assessment of venous thromboembolic risk in surgical patients. Semin Thromb Hemost; 17 (Suppl 3): 304-3I 2.

46. Caprini JA (2005) Thrombosis risk assessment as a guide to quality patient care. Dis Mon; $5 \mathrm{I}$ : 70-74.
47. Ay C, Pabinger I (20I5) VTE risk assessment in cancer. Who needs prophylaxis and who does not? Hamostaseologie; 35: 319-324.

48. Bouras G, Burns EM, Howell AM, Bottle A, Athanasiou T, Darzi A (2015) Risk of Post-Discharge Venous Thromboembolism and Associated Mortality in General Surgery: A Population-Based Cohort Study Using Linked Hospital and Primary Care Data in England. PLoS One; 10: e0I45759.

49. Törngren S, Rieger A (1982) Prophylaxis of deep venous thrombosis in colorectal surgery. Dis Colon Rectum; 25: 563-566.

50. Geerts WH, Pineo GF, Heit JA et al (2004) Prevention of venous thromboembolism: the Seventh ACCP Conference on Antithrombotic and Thrombolytic Therapy. Chest; 126 (3 Suppl): 338S-400S.

51. Heit JA, Silverstein MD, Mohr DN et al (2000) Risk factors for deep vein thrombosis and pulmonary embolism: a population-based case-control study. Arch Intern Med; 160: 809-815.

52. Merkow RP, Bilimoria KY, McCarter MD et al (201I) Post-discharge venous thromboembolism after cancer surgery: extending the case for extended prophylaxis. Ann Surg; 254: |3|-137.

53. Alsubaie $H$, Leggett $C$, Lambert $P$ et al (2015) Diagnosis of VTE postdischarge for major abdominal and pelvic oncologic surgery: implications for a change in practice. Can J Surg; 58: 305-3II.

54. Larsen AC, Frøkjær JB, Fisker RV et al (2015) Treatment-related frequency of venous thrombosis in lower esophageal, gastro-esophageal and gastric cancer - a clinical prospective study of outcome and prognostic factors. Thromb Res; 135: 802-808.

55. Lodders JN, Parmar S, Stienen NL et al (2015) Incidence of symptomatic venous thromboembolism in oncological oral and maxillofacial operations: retrospective analysis. $\mathrm{Br} J$ Oral Maxillofac Surg; 53: 244-250.

56. Chiesa Estomba C, Rivera Schmitz T, Ossa Echeverri CC, Betances Reinoso FA, Osorio Velasquez A, Santidrian Hidalgo C (2015) The risk of venous thromboembolism in ENT and head \& neck surgery. Otolaryngol Pol; 69: 3I-64.

57. Kakei Y, Akashi M, Hasegawa T, Minamikawa T, Usami S, Komori T (2016) Incidence of Venous Thromboembolism After Oral Oncologic Surgery With Simultaneous Reconstruction. J Oral Maxillofac Surg; 74: 212-217.

58. Tran BH, Nguyen TJ, Hwang BH et al (2013) Risk factors associated with venous thromboembolism in 49,028 mastectomy patients. Breast; 22: 444-448.

59. De Martino RR, Goodney PP, Spangler EL et al (2012) Variation in thromboembolic complications among patients undergoing commonly performed cancer operations. J Vasc Surg; 55: 1035-1040.

60. Lovely JK, Nehring SA, Boughey JC Et al (2012) Balancing venous thromboembolism and hematoma after breast surgery. Ann Surg Oncol; 19: 3230-3235.

61. Clagett GP, Reisch JS (1998) Prevention of venous thromboembolism in general surgical patients. Ann Surg; 208: 227-240.

62. Wille-Jørgensen P, Kjaergaard J ( 1985) Prophylaxis of postoperative deep venous thrombosis. JAMA; 253: 1120.

63. Bergqvist D, Burmark US, Friselli J et al (1986) Low molecular weight heparin once daily compared with conventional low- 
-dose heparin twice daily. A prospective double-blind multicentre trial on prevention of postoperative thrombosis. $\mathrm{Br} J$ Surg; 73: 204-208.

64. Bergqvist D, Matzsch T, Friselli J et al (1988) Low molecular weight heparin given in the evening before surgery compared with conventional low-dose heparin in the prevention of thrombosis. Br J Surg; 75: 888-891.

65. Samama M, Bernard P, Bonnardot JP, Combe-Tamzali S, Lanson Y, Tissot E (1988) Low molecular weight heparin compared with unfractionated heparin in the prevention of postoperative thrombosis. Br J Surg; 75: |28-13|.

66. Leizorovicz A, Picolet H, Peyrieux JC, Boissel JP (1991) Prevention of postoperative deep vein thrombosis in general surgery: a multicenter double-blind study comparing two doses of logiparin and standard heparin. Br J Surg; 78: 412-416.

67. Boneu B (1993) An international multicenter study: Clivarin in the prevention of venous thromboembolism in patients undergoing general surgery. Blood Coagul Fibrinol; 4 (Suppl): S2I-S22.

68. ENOXACAN Study Group (1997) Efficacy and safety of enoxaparin versus unfractionated heparin for prevention of deep vein thrombosis in elective cancer surgery: a double-blind randomized multicentre trial with venographic assessment. $\mathrm{Br} J$ Surg; 84: 1099-1103.

69. Kakkar W, Cohen AT, Edmonson RA et al (1993) Low molecular weight versus standard heparin for prevention of venous thromboembolism after major abdominal surgery. The Thromboprophylaxis Collaborative Group. Lancet; 34I: 259-265.

70. The European Fraxiparin Study (EFS) Group (1988) Comparison of a low molecular weight heparin and unfractionated heparin for the prevention of deep vein thrombosis in patients undergoing abdominal surgery. Br J Surg; 75: 1058-1063.

71. Baykal C, Al A, Demirtas E, Ayhan A (200I) Comparison of enoxaparin and standard heparin in gynaecologic oncologic surgery: a randomized prospective double-blind clinical study. Eur J Gynaecol Oncol; 22: 127-130.

72. Akl EA, Kahale L, Sperati $F$ et al (20/4) Low molecular weight heparin versus unfractionated heparin for perioperative thromboprophylaxis in patients with cancer. Cochrane Database Syst Rev; 6: CD009447.

73. Bergqvist D, Burmark US, Flordal PA et al (1995) Low molecular weight heparin started before surgery as prophylaxis against deep vein thrombosis: 2500 vs 5000 Xa IU in 2070 patients. $\mathrm{Br}$ J Surg; 82: 496-50I.

74. Kakkar AK, Agnelli G, George D et al (20II) The ultra-low-molecular-weight heparin semuloparin for prevention of venous thromboembolism in patients undergoing major abdominal surgery. Presented at the 53rd Annual Meeting of the American Society of Hematology, San Diego, CA, 20II, December 10-13, 2011.

75. Simonneau G, Laporte S, Mismetti P et al (2006) A randomized study comparing the efficacy and safety of nadroparin $2850 \mathrm{IU}$ $(0.3 \mathrm{~mL})$ vs. enoxaparin $4000 \mathrm{IU}(40 \mathrm{mg})$ in the prevention of venous thromboembolism after colorectal surgery for cancer. J Thromb Haemost; 4: 1693-1700.

76. Agnelli G, Bergqvist D, Cohen A, Gallus AS, Gent M; PEGASUS investigators (2005) Randomized clinical trial of postoperative fondaparinux versus perioperative dalteparin for prevention of venous thromboembolismin high-risk abdominal surgery. $\mathrm{Br}$ J Surg; 92: 1212-1220.
77. Yamaoka $Y$, Ikeda M, Ikenaga M, Haraguchi N, Miyake M, Sekimoto $M(2015)$ Safety and efficacy of fondaparinux for prophylaxis of venous thromboembolism after colorectal cancer resection: a propensity score matched analysis. Dig Surg; 32: 190-195.

78. Bergqvist D, Agnelli G, Cohen AT et al (2002) Duration of prophylaxis against venous thromboembolism with enoxaparin after surgery for cancer. N Engl J Med; 346: 975-980.

79. Rasmussen MS, Jorgensen LN, Wille-Jørgensen $P$ et al (2006) Prolongedprophylaxis with dalteparin to prevent late thromboembolic complications in patients undergoing major abdominal surgery: a multicenter randomized open-label study. J Thromb Haemost; 4: 2384-2390.

80. Lausen I, Jensen R, Jorgensen LN et al (1998) Incidence and prevention of deep venous thrombosis occurring late after general surgery: randomised controlled study of prolonged thromboprophylaxis. Eur J Surg; 164: 657-663.

8I. Kakkar W, Balibrea JL, Martinez-Gonzalez J, Prandoni P; CANBESURE Study Group (2010) Extended prophylaxis with bemiparin for the prevention of venous thromboembolism after abdominal or pelvic surgery for cancer: the CANBESURE randomized study. J Thromb Haemost; 8: 1223-1229.

82. AkI EA, Terrenato I, Barba M, Sperati F, Muti P, Schünemann HJ (2008) Extended perioperative thromboprophylaxis in patients with cancer. A systematic review. Thromb Haemost; 100: I176-1180.

83. Sakon M, Kobayashi T, Shimazui T (2010) Efficacy and safety of enoxaparin in Japanese patients undergoing curative abdominal or pelvic cancer surgery: Results from a multicenter, randomized, openlabel study. Thromb Res; 125: e65-e70.

84. Nagata C, Tanabe H, Takakura S et al (2015) Randomized controlled trial of enoxaparin versus intermittent pneumatic compression for venous thromboembolism prevention in Japanese surgical patients with gynecologic malignancy. J Obstet Gynaecol Res; 4I: |440-1448.

85. Song KY, Yoo HM, Kim EY et al (20/4) Optimal prophylactic method of venous thromboembolism for gastrectomy in Korean patients: an interim analysis of prospective randomized trial. Ann Surg Oncol; 21: 4232-4238.

86. Wang JP, Lin YD, Wang $L$ et al (2013) Effect of intermittent pneumatic compression on coagulation function and deep venous hemodynamics of lower limbs after rectal cancer resection. Zhonghua Wei Chang Wai Ke Za Zhi; 16: 739-743.

87. Ramirez JI, Vassiliu P, Gonzalez-Ruiz C et al (2003) Sequential compression devices as prophylaxis for venous thromboembolism in high-risk colorectal surgery patients: reconsidering American Society of Colorectal Surgeons parameters. Am Surg; 69: 94I-945.

88. Zareba P, Wu C, Agzarian J, Rodriguez D, Kearon C (2014) Meta-analysis of randomized trials comparing combined compression and anticoagulation with either modality alone for prevention of venous thromboembolism after surgery. $\mathrm{Br}$ J Surg; 101: 1053-1062.

89. Yasui M, Ikeda M, Miyake M et al (2015) Comparison of bleeding risks related to venous thromboembolism prophylaxis in laparoscopic vs open colorectal cancer surgery: a multicenter study in Japanese patients. Am J Surg; 21 3: 43-49.

90. Kimura Y, Oki E, Ando K, Saeki H, Kusumoto T, Maehara Y (2016) Incidence of Venous Thromboembolism Following Lapa- 
roscopic Surgery for Gastrointestinal Cancer: A Single-Center, Prospective Cohort Study. World J Surg; 40: 309-3I4.

91. Xie YZ, Fang K, Ma WL, Shi ZH, Ren XQ (2015) Risk of postoperative deep venous thrombosis in patients with colorectal cancer treated with open or laparoscopic colorectal surgery: a meta-analysis. Indian J Cancer; 5I suppl 2: e42-44.

92. Society of American Gastrointestinal and Endoscopic Surgeons (SAGES) Guidelines Committee (2007) Guidelines for deep venous thrombosis prophylaxis during laparoscopic surgery. Surg Endosc; 21: 1007-1009.

93. Vedovati MC, Becattini C, Rondelli F et al (2014) A randomized study on I-week versus 4-week prophylaxis for venous thromboembolism after laparoscopic surgery for colorectal cancer. Ann Surg; 259: 665-669.

94. Khorana AA, Francis CW, Culakova E, Kuderer NM, Lyman GH (2007) Frequency, risk factors, and trends for venous thromboembolism among hospitalized cancer patients. Cancer; 110 : 2339-2346.

95. Vitale C, D'Amato M, Calabrò P, Stanziola AA, Mormile M, Molino A (2015) Venous thromboembolism and lung cancer: a review. Multidiscip Respir Med; 10: 28.

96. Zhang Y, Yang Y, Chen W et al (2014) Prevalence and associations of VTE in patients with newly diagnosed lung cancer. Chest; 146: 650-658.

97. Steuer CE, Behera M, Kim S et al (2015) Predictors and outcomes of venous thromboembolism in hospitalized lung cancer patients: A Nationwide Inpatient Sample database analysis. Lung Cancer; 88: 80-84.

98. Dentali F, Malato A, Ageno W et al (2008) Incidence of venous thromboembolism in patients undergoing thoracotomy for lung cancer. J Thorac Cardiovasc Surg; 135: 705-706.

99. Kalweit G, Huwer H, Volkmer I, Petzold T, Gams E (1996) Pulmonary embolism: a frequent cause of acute fatality after lung resection. Eur J Cardiothorac Surg; 104: 242-247.

100. White RH, Zhou H, Romano PS (2003) Incidence of symptomatic venous thromboembolism after different elective or urgent surgical procedures. Thromb Haemost; 903:446-455.

10 I. Mason DP, Quader MA, Blackstone EH et al (2006) Thromboembolism after pneumonectomy for malignancy: an independent marker of poor outcome. J Thorac Cardiovasc Surg; 1313: 71 I-718.

102. Weder W, Collaud S, Eberhardt WE et al (2010) Pneumonectomy is a valuable treatment option after neoadjuvant therapy for stage III non-small-cell lung cancer. J Thorac Cardiovasc Surg; 139: | 424-1430.

103. Hachey KJ, Hewes PD, Porter LP et al (2016) Caprini venous thromboembolism risk assessment permits selection for postdischarge prophylactic anticoagulation in patients with resectable lung cancer. J Thorac Cardiovasc Surg; 151: 37-44.

104. Sugarbaker DJ, Jaklitsch MT, Bueno R et al (2004) Prevention, early detection, and management of complications after 328 consecutive extrapleural pneumonectomies. J Thorac Cardiovasc Surg; 1281: 138-146.

105. Christensen TD, Vad H, Pedersen S et al (2014) Venous thromboembolism in patients undergoing operations for lung cancer: a systematic review. Ann Thorac Surg; 97: 394-400.

106. Gómez-Hernández MT, Rodríguez-Pérez M, Novoa-Valentín N, Jiménez-López M, Aranda-Alcaide JL, Varela-Simó G (2013) Prevalence of venous thromboembolism in elective thoracic surgery. Arch Bronconeumol; 49: 272-302.
107. Świniarska J, Zekanowska E, Dancewicz M, Bella M, Szczesny T], Kowalewski JJ (2009) Pneumonectomy due to lung cancer results in a more pronounced activation of coagulation system than lobectomy. Eur J Cardiothorac Surg; 36: 1064-1068.

108. Yang Y, Zhou Z, Niu XM et al (2012) Clinical analysis of postoperative venous thromboembolism risk factors in lung cancer patients. J Surg Oncol; 106: 736-74I.

109. Kadlec B, Skrickova J, Merta Z, Dusek L, Jarkovsky J (2014) The incidence and predictors of thromboembolic events in patients with lung cancer. Scientific World J; 125706.

1 10. Ziomek S, Read RC, Tobler HG et al (1993) Thromboembolism in patients undergoing thoracotomy. Ann Thorac Surg; 562: 223-227.

III. Ljungström KG ( 1985) Deep-vein thrombosis after major non-cardiovascular thoracic surgery. Scand J Thorac Cardiovasc Surg; 192: 161-164.

1 12. Daddi G, Milillo G, Lupattelli L et al (2006) Pulmonary Embolism in Thoracic Surgery Study Group Pulmonary Embolism in Thoracic Surgery Study Group Postoperative pulmonary embolism detected with multislice computed tomography in lung surgery for cancer. J Thorac Cardiovasc Surg; 1321: 197-198.

1 13. Nagahiro I, Andou A, Aoe M, Sano Y, Date H, Shimizu N (2004) Intermittent pneumatic compression is effective in preventing symptomatic pulmonary embolism after thoracic surgery. Surg Today; 34: 6-10.

114. Geerts W, Bergqvist D, Pineo G et al (2008) Prevention of Venous Thromboembolism. American College of Chest Physicians Evidence-Based Clinical Practice Guidelines (8th Edition). Chest; 133: 38IS-453S.

115. Detterbeck FC (200I) Diagnosis and Treatment of Lung Cancer: An Evidence-Based Guide for the Practicing Clinician. WB Saunders, Philadelphia.

1 16. Cade JF, Clegg EA, Westlake GW (1983) Prophylaxis of venous thrombosis after major thoracic surgery. Aust NZJ Surg; 53: 30I-304.

I 17. Azorin JF, Regnard JF, Dahan M et al (1997) Efficacy and tolerability of Fraxiparine in the prevention of thromboembolic events in lung cancer. Ann Cardiol Angiol; 27I: 34I-347.

I 18. Di Nisio M, Peinemann F, Porreca E, Rutjes AW (2015) Primary prophylaxis for venous thromboembolism in patients undergoing cardiac or thoracic surgery. Cochrane Database Syst Rev; 6: CD009658.

1 19. Rahn DD, Mamik MM, Sanses TV et al (201I) Society of Gynecologic Surgeons Systematic Review Group Venous thromboembolism prophylaxis in gynecologic surgery: a systematic review. Obstet Gynecol; I I8: I I I I-I I 25.

120. Morimoto A, Ueda Y, Yokoi T et al (2014) Perioperative venous thromboembolism in patients with gynecological malignancies: a lesson from four years of recent clinical experience. Anticancer Res; 34: 3589-3595.

121. Tateo S, Mereu L, Salamano S et al (2005) Ovarian cancer and venous thromboembolic risk. Gynecol Oncol; 99: II9-125.

122. Abu Saadeh F, Norris L, O'Toole S, Gleeson N (2013) Venous thromboembolism in ovarian cancer: incidence, risk factors and impact on survival. Eur J Obstet Gynecol Reprod Biol; 170: 214-218.

123. Morimoto A, Ueda Y, Yokoi T et al (2014) Perioperative venous thromboembolism in patients with gynecological malignancies: 
a lesson from four years of recent clinical experience. Anticancer Res; 34: 3589-3595.

124. Peedicayil A, Weaver A, Li X (20 I I) Incidence and timing of venous thromboembolism after surgery for gynecological cancer. Gynecol Oncol; 121: 64-69.

125. Oranratanaphan S, Termrungruanglert W, Khemapech N (2015) Incidence and Clinical Characteristic of Venous Thromboembolism in Gynecologic Oncology Patients attending King Chulalongkorn Memorial Hospital over a 10 Year Period. Asian Pac Cancer Prev; 16: 6705-6709.

126. Heath OM, van Beekhuizen HJ, Nama V et al (2016) Venous thromboembolism at time of diagnosis of ovarian cancer: Survival differs in symptomatic and asymptomatic cases. Thromb Res; 137: 30-35.

127. Krasiński Z, Szpurek D, Staniszewski R et al (2014) The value of extended preoperative thromboprophylaxis with dalteparin in patients with ovarian cancer qualified to surgical treatment. Int Angiol; 33: 365-367.

128. Clarke-Pearson DL, Abaid LN (2012) Prevention of venous thromboembolic events after gynecologic surgery. Obstet Gynecol; । 19: 155-167.

129. Heilmann L, von Tempelhoff GF, Schneider D (1998) Prevention of thrombosis in gynecologic malignancy. Clin Appl Thromb Hemost; 4: 153-159.

130. Ward B, Pradhan S (1998) Comparison of low molecular weight heparin (Fragmin) with sodium heparin for prophylaxis against postoperative thrombosis in women undergoing major gynaecological surgery. Aust NZJ Obstet Gynaecol; 38: 91-92.

13I. Baykal C, Al A, Demirtas E et al (200I) Comparison of enoxaparin and standard heparin in gynaecologic oncologic surgery: a randomised prospective double-blind clinical study. Eur J Gynaec Oncol; 22: 127-130.

132. Maxwell GL, Synan I, Dodge R et al (200I) Pneumatic compression versus low molecular weight heparin in gynecologic oncology surgery: a randomized trial. Obstet Gynecol; 98: 989-995.

133. Oates-Whitehead RM, D'Angelo A, Mol B (2003) Anticoagulant and aspirin prophylaxis for preventing thromboembolismafter major gynaecological surgery. Cochrane Database Syst Rev; 4: CD003679.

134. Baykal C, Al A, Demirtas E et al (200I) Comparison of enoxaparin and standard heparin in gynaecologic oncologic surgery: a randomised prospective double-blind clinical study. Eur J Gynaec Oncol; 22: 127-130.

135. Fricker JP, Vergnes Y, Schach R et al (1988) Low dose heparin versus low molecular weight heparin (Kabi 2165, Fragmin) in the prophylaxis of thromboembolic complications of abdominal oncological surgery. Eur J Clin Invest; 18: 56I-567.

136. Heilmann L, von Templehoff GF, Kirkpatrick C et al (1998) Comparison of unfractionated versus low molecular weight heparin for deep vein thrombosis prophylaxis during breastand pelvic cancer surgery: efficacy, safety, and follow-up. Clin Appl Thromb/Hemost; 4: 268-273.

137. Bouchard-Fortier G, Geerts WH, Covens A, Vicus D, Kupets R, Gien LT (2014) Is venous thromboprophylaxis necessary in patients undergoing minimally invasive surgery for a gynecologic malignancy? Gynecol Oncol; 134: 228-232.

138. Ageno W, Manfredi E, Dentali F et al (2007) The incidence of venous thromboembolism following gynecologic laparoscopy: a multicenter, prospective cohort study. J Thromb Haemost; 5: 503-506.
139. Abu-Rustum NR, Chi DS, Sonoda Y et al (2003) Transperitoneal laparoscopic pelvic and para-aortic lymph node dissection using the argon-beam coagulator and monopolar instruments: an 8-year study and description of technique. Gynecol Oncol; 89: 504-513.

140. Panici PB, Plotti F, Zullo MA et al (2006) Pelvic lymphadenectomy for cervical carcinoma: laparotomy extraperitoneal, transperitoneal or laparoscopic approach? A randomized study. Gynecol Oncol; 103: 859-864.

14I. Einstein MH, Pritts EA, Hartenbach EM (2007) Venous thromboembolism prevention in gynecologic cancer surgery: a systematic review. Gynecol Oncol; 105: 813-819.

142. Clarke-Pearson DL, DeLong E, Synan IS et al (1990) A controlled trial of two low-dose heparin regimens for the prevention of postoperative deep vein thrombosis. Obstet Gynecol; 75: 684-689.

143. Clarke-Pearson DL, Synan IS, Dodge R et al (1993) A randomized trial of low-dose heparin and intermittent pneumatic calf compression for the prevention of deep venous thrombosis after gynecologic oncology surgery. Am J Obstet Gynecol; 168: II 46-II 54.

144. Stroud W, Whitworth JM, Miklic M et al (2014) Validation of a venous thromboembolism risk assessment model in gynecologic oncology. Gynecol Oncol; 134: 160-163.

145. Maxwell GL, Synan I, Dodge R et al (200I) Pneumatic compression versus low molecular weight heparin in gynecologic oncology surgery: a randomized trial. Obstet Gynecol; 98: 989-995.

146. Khaldi A, Helo N, Schneck MJ, Origitano TC (20II) Venous thromboembolism: deep venous thrombosis and pulmonary embolism in a neurosurgical population. J Neurosurg; I I4: $40-46$.

147. Portillo J, de la Rocha IV, Font $L$ et al (2015) Venous thromboembolism in patients with glioblastoma multiforme: Findings of the RIETE registry. Thromb Res; 136: I199-1203.

148. Streiff MB, Ye X, Kickler TS et al (2015) A prospective multicenter study of venous thromboembolism in patients with newly-diagnosed high-grade glioma: hazard rate and risk factors. J Neurooncol; 124: 299-305.

149. Taillibert S, Taillandier L, Le Rhun E (2015) Venous thrombosis in patients with high-grade glioma. Curr Opin Oncol; 27: 516-521.

150. Salmaggi A, Simonetti G, Trevisan E et al (2013) Perioperative thromboprophylaxis in patients with craniotomy for brain tumours: a systematic review. J Neurooncol; I I 3: 293-303.

15I. Collen JF, Jackson JL, Shorr AF, Moores LK (2008) Prevention of venous thromboembolism in neurosurgery: a meta-analysis. Chest; 134: 237-249.

152. Hamilton MG, Yee WH, Hull RD, Ghali WA (20II) Venous thromboembolism prophylaxis in patients undergoing cranial neurosurgery: a systematic review and metaanalysis. Neurosurgery; 68: 57I-58I.

153. Smith TR, Nanney AD 3rd, Lall RR et al (2015) Development of venous thromboembolism (VTE) in patients undergoing surgery for brain tumors: results from a single center over a 10 year period. J Clin Neurosci; 22: 519-525.

154. Smith TR, Lall RR, Graham RB et al (2014) Venous thromboembolism in high grade glioma among surgical patients: results from a single center over a 10 year period. J Neurooncol; 120 : 347-352. 
155. Brandes AA, Scelzi E, Salmistraro G et al (1997) Incidence of risk of thromboembolism during treatment high-grade gliomas: a prospective study. Eur J Cancer; 33: 1592-1596.

156. Marras LC, Geerts WH, Perry JR (2000) The risk of venous thromboembolism is increased throughout the course of malignant glioma: an evidence-based review. Cancer; 89: 640-646.

157. Ruff RL, Posner JB (1983) Incidence and treatment of peripheral venous thrombosis in patients with gloma. Ann Neurol; 13: 334-336.

158. Walsh DC, Kakkar AK (200I) Thromboembolism in brain tumors. Curr Opin Pulm Med; 7: 326-331.

159. Semrad TJ, O'Donnell R, Wun T et al (2007) Epidemiology of venous thromboembolism in 9489 patients with malignant glioma. J Neurosurg; 106: 60I-608.

160. Jenkins EO, Schiff D, Mackman N, Key NS (2010) Venous thromboembolism in malignant gliomas. J Thromb Haemost; 8: $221-227$

16I. Yust-Katz S, Mandel JJ, Wu J et al (2015) Venous Thromboembolism (VTE) and glioblastoma. J Neurooncol; 124: 87-94.

162. Chan AT, Atiemo A, Diran LK et al (1999) Venous thromboembolism occurs frequently in patients undergoing brain tumor surgery despite prophylaxis. J Thromb Thrombolysis; 8: 139-142.

163. Simanek R, Vormittag R, Hassler M et al (2007) Venous thromboembolism and survival in patients with high-grade glioma. Neuro Oncol; 9: 89-95.

164. Kimmel KT, Walter KA (2014) Risk factors for venous thromboembolism in patients undergoing craniotomy for neoplastic disease. J Neurooncol; 120: 567-573.

165. Turpie AG, Gallus A, Beattie WS, Hirsh J (1977) Prevention of venous thrombosis in patients with intracranial disease by intermittent pneumatic compression of the calf. Neurology; 27: 435-438.

166. Skillman JJ, Collins RE, Coe NP et al (1978) Prevention of deep vein thrombosis in neurosurgical patients: a controlled, randomized trial of external pneumatic compression boots. Surgery; 83: 354-358.

167. Bucci MN, Papadopoulos SM, Chen JC et al (1989) Mechanical prophylaxis of venous thrombosis in patients undergoing craniotomy: a randomized trial. Surg Neurol; 32: 285-288.

168. Agnelli G, Piovella F, Buoncristiani P et al (1998) Enoxaparin plus compression stockings compared with compression stockings alone in the prevention of venous thromboembolism after elective neurosurgery. N Engl J Med; 339: 80-85.

169. Turpie AG, Hirsh J, Gent M, Julian D, Johnson J (1989) Prevention of deep vein thrombosis in potential neurosurgical patients. A randomized trial comparing graduated compression stockings alone or graduated compression stockings plus intermittent pneumatic compression with control. Arch Intern Med; 149: 679-68I.

170. Wautrecht JC, Macquaire V, Vandesteene A et al (1996) Prevention of deep vein thrombosis in neurosurgical patients withbrain tumors: a controlled, randomized study comparing graded compression stockings alone and with intermittent sequential compression: correlation with pre- and post-operative fibrinolysis; preliminary results. Int Angiol; 15 (suppl I): 5-10.

17I. Sobieraj-Teague M, Hirsh J, Yip G et al (20I2) Randomized controlled trial of a new portable calf compression device (Venowave) for prevention of venous thrombosis in high-risk neurosurgical patients. J Thromb Haemost; 10: 229-235.
172. lorio A, Agnelli G (2000) Low-molecular-weight and unfractionated heparin for prevention of venous thromboembolism in neurosurgery: a meta-analysis. Arch Intern Med; 160: 2327-2332.

173. Dickinson LD, Miller LD, Patel CP, Gupta SK (1998) Enoxaparin increases the incidence of postoperative intracranial hemorrhage when initiated preoperatively for deep venous thrombosis prophylaxis in patients with brain tumors. Neurosurgery; 43 : 1074-1081.

174. Nurmohamed MT, van Riel AM, Henkens CM et al (1996) Low molecular weight heparin and compression stockings in the prevention of venous thromboembolism in neurosurgery. Thromb Haemost; 75: 233-238.

175. Cerrato D, Ariano C, Fiacchino F (1978) Deep vein thrombosis and low-dose heparin prophylaxis in neurosurgical patients. J Neurosurg; 49: 378-38I.

176. Constantini S, Kanner A, Friedman A et al (200I) Safety of perioperative minidose heparin in patients undergoing brain tumor surgery: a prospective, randomized, double-blind study. J Neurosurg; 94: 918-921.

177. Goldhaber SZ, Dunn K, Gerhard-Herman M, Park JK, Black PM (2002) Low rate of venous thromboembolism after craniotomy for brain tumor using multimodality prophylaxis. Chest; 122: 1933-1937.

178. MacDonald RL, Amidei C, Baron J et al (2003) Randomized, pilot study of intermittent pneumatic compression devices plus dalteparin versus intermittent pneumatic compression devices plus heparin for prevention of venous thromboembolism in patients undergoing craniotomy. Surg Neurol; 59: 363-372.

179. Samama CM, Albaladejo P, Benhamou D et al (2006) Venous thromboembolism Prevention in surgery and obstetrics: clinical practical guidelines. Eur J Anaesthesiol; 23: 95-II6.

180. Forrest JB, Clemens JQ, Finamore P (2009) AUA best practice statement for the prevention of deep vein thrombosis in patients undergoing urologic surgery. J Urol; I81: I I70-I 177.

181. Colby FU (1948) The prevention of fatal pulmnoary emboli after prostatectomy. J Urol; 59: 920.

182. Gordon-Smith IC, Hickman JA, el-Masri SH (1972) The efect of the fibrinolytic inhibitor epsilonaminocaproic amid on the incidence of deep-vein thrombosis after prostatectomy. $\mathrm{Br} J$ Surg; 59: 599.

183. Nicolaides AN, Fidel ES, Kakkar W et al (1972) Prostatectomy and deep vein thrombosis. $\mathrm{Br}$ J Surg; 59: 487.

184. Thomas PJ, Nurse DE, Deliveliotis C et al (1992) Cystoprostatectomy and substitution cystoplasty for locally invasive blader cancer. Br J Urol; 70: 40.

185. Alberts BD, WolduSL, WeinbergAC, DanzigMR, Korets R, Badani KK (2014) Venous thromboembolism after major urologic oncology surgery: a focus on the incidence and timing of thromboembolic events after 27,455 operations. Urology; 84:799-806.

186. Potretzke AM, Wong KS, Shi F, Christensen W, Downs TM, Abel EJ (20I5) Highest risk of symptomatic venous thromboembolic events after radical cystectomy occurs in patients with obesity or nonurothelial cancers. Urol Ann; 7: 355-360.

187. VanDlac AA, Cowan NG, Chen $Y$ et al (2014) Timing, incidence and risk factors for venous thromboembolism in patients undergoing radical cystectomy for malignancy: a case for extended duration pharmacological prophylaxis. J Urol; 191: 943-947. 
188. Rosario DJ, Becker M, Anderson JB (2000) The changing pattern of mortality and morbidity from radical cystectomy. BJU Int; 85: 427-430.

189. James AC, Holt SK, Wright JL, Porter MP, Gore JL (2014) Burden and timing of venothrombolic events in patients younger than 65 years undergoing radical cystectomy for bladder cancer. Urol Oncol; 32: 815-819.

190. White RH, Zhou H, Romano PS (2003) Incidence of symptomatic venous thromboembolism after different elective or urgent surgical procedures. Thromb Haemost; 90: 446-455.

191. Heinzer H, Hammerer P, Graefen M et al (1998) Thromboembolic complication rate after radical retropubic prostatectomy. Impact of routine ultrasonography for the detection of pelvic lymphocele and hematomas. Eur Urol; 33: 86-90.

192. Leibovitch I, Foster RS, Wass JL et al (1995) Color Doppler flow imaging for deepvenous thrombosis screening in patients undergoing pelvic lymphadenectomy and radical retropubic prostatectomy for prostatic carcinoma. J Urol; 153: 1866$-1869$.

193. Hautman RE, Sauter TW, Wendroth UK (1994) Radical retropubic prostatectomy: morbidity and urinary continence in 418 consecutive casus. Urology; 43 (2 Suppl); 47-5I.

194. Leandri P, Rossignol G, Gautier JR, Ramon J (1992) Radical retropubic prostatectomy: morbidity and quality of life. Experience with 620 consecutive cases. J Urol; 147: 883.

195. Pedersen KV, Herder A (1993) Radical retropubic prostatectomy for localized prostatic carcinoma: a clinical and pathological study of 20I cases. Scand J Urol Nephrol; 27: 2219.

196. Shekarriz B, Upadhyay J, Wood DP (200I) Intraoperative, perioperative and long term complications of radical prostatectomy. Urol Clin North Am; 28: 639-643.

197. Andriole GL, Smith DS, Rao G et al (1994) Early complications of contemporary anatomical radical retropubic prostatectomy. J Urol; 152: 1858-1960.

198. Dillioglugil O, Leibman BD, Leibman NS et al (1997) Risk factors for complications and morbidity after radical retropubic prostatectomy. J Urol; 157: 1760-1767.

199. Lerner SE, Blute ML, Lieber MM et al (1995) Morbidity of contemporary radical retropubic prostatectomy for localized prostate cancer. Oncology (Huntingt); 9: 375.

200. Catalona WJ, Carvalhal GF, Mager DE et al (1999) Potency, continence and complication rates in 1870 consecutive radical retropubic prostatectomies. J Urol; 162: 433.

20I. Hammond J, Kozma C, Hart JC et al (20II) Rates of venous thromboembolism among patients with major surgery for cancer. Ann Surg Oncol; 18: 3240-3247.

202. Kakkar $\vee(1972)$ The diagnosis of deep vein thrombosis using the I25I fibrinogen test. Arch Surg; 104: 152-159.

203. Beyer J, Wessela S, Hakenberg OW et al (2009) Incidence, risk profile and morphological pattern of venous thromboembolism after prostate cancer surgery. J Thromb Haemost; 7: 597-604.

204. Chan SY, Leung VF, Yee CH et al (2014) Incidence of postoperative deep vein thrombosis after robotic-assisted laparoscopic prostatectomy: a prospective study in Chinese patients. Int Urol Nephrol; 46: 2139-2।42.

205. Sawczuk IS, Williams D, Chang DT (2002). Low molecular weight heparin for venous thromboembolism prophylaxis in urologic onclolgic surgery. Cancer Invest; 20: 7/8: 889-892.
206. Kibel AS, Loughlin KR (1995) Pathogenesis and prophylaxis of postooperative thromboembolic disease in urological pelvic surgery. J Urol; 153: 1763.

207. Potretzke AM, Wong KS, Shi F, Christensen W, Downs TM, Abel EJ (2015) Highest risk of symptomatic venous thromboembolic events after radical cystectomy occurs in patients with obesity or nonurothelial cancers. Urol Ann; 7: 355-360.

208. O'Farrell S, Sandström K, Garmo H et al (2016) Risk of thromboembolic disease in men with prostate cancer undergoing androgen deprivation. BJU Int; I 18: 391-398.

209. Pettus JA, Eggener SE, Shabsigh A et al (2006) Perioperative clinical thromboembolic events after radical or partial nephrectomy. Urology; 68: 988-992.

210. Smith AB, Horvath-Puhó E, Nielsen ME, Lash T, Baron JA, Sorensen $\mathrm{H}$ (2014) Effect of comorbidity on risk of venous thromboembolism in patients with renal cell carcinoma. Urol Oncol; 32: 466-472.

21I. Ihaddadene R, Yokom DW, Le Gal G et al (2014)The risk of venous thromboembolism in renal cell carcinoma patients with residual tumor thrombus. J Thromb Haemost; 12: 855-859.

212. Yokom DW, Ihaddadene R, Moretto P et al (2014) Increased risk of preoperative venous thromboembolism in patients with renal cell carcinoma and tumor thrombus. J Thromb Haemost; |2: |69-17|.

213. Kavoussi LR, Sosa E, Chandhoke P et al (1993) Complications of laparoscopic pelvix lymph node dissection. J Urol; I49: 322.

214. Caddedu JA, Wolf JS, Nakada S et al (200I) Complications of laparoscopic procedures after concentrated training in urological laparoscopy. J Urol; 166: 2109.

215. Fahlenkamp D, Rassweiler J, Fornanra P et al (1999) Complications of laparoscopic procedures in urology: experience with 2407 procedures at 4 German centers. J Urol; 162: 765.

216. Rassweiler JJ, Semmann O, Frede T et al (1998) Retroperitoneoscopy: experience with 200 cases. J Urol; 160: 1265.

217. Trabulsi EJ, Guillonneau B (2005) Laparoscopic radical prostatectomy. J Urol; 173: 1072-1079.

218. Montgomery JS, Wolf JS Jr (2005) Venous thrombosis prophylaxis for urological laparoscopy: fractionated heparin versus sequential compression devices. J Urol; 173: 1623-1626.

219. Permpongkosol S, Link RE, Su LM et al (2007) Complications of 2,775 urological laparoscopic procedures: 1993 to 2005. J Urol; 177: 580-585.

220. Secin FP, Jiborn T, Bjartell AS et al (2008) Multi-institutional study of symptomatic deep venous thrombosis and pulmonary embolism in prostate cancer patients undergoing laparoscopic or robot-assisted laparoscopic radical prostatectomy. Eur Urol; 53: 134-145.

22I. Chalmers DJ, Scarpato KR, Staff I et al (2013) Does heparin prophylaxis reduce the risk of venous thromboembolism in patients undergoing robot-assisted prostatectomy? J Endourol; 27: 800-803.

222. Patel T, Kirby W, Hruby G, Benson MC, McKiernan JM, Badani K (20II) Heparin prophylaxis and the risk of venous thromboembolism after robotic-assisted laparoscopic prostatectomy. BJU Int; 108: 729-732.

223. Abel EJ, Wong K, Sado M et al (2014) Surgical operative time increases the risk of deep venous thrombosis and pulmonary embolism in robotic prostatectomy. JSLS; 18: 282-287.

224. Donat R, Mancey-Jones B (2002) Incidence of thromboembolism after transurethral resection of the prostate (TURP). 
A study of TED stocking prophylaxis and literature review. Scand J Urol Nephrol; 36: II9-123.

225. Tikkinen KA, Agarwal A, Craigie S (2014) Systematic reviews of observational studies of risk of thrombosis and bleeding in urological surgery (ROTBUS): introduction and methodology. Syst Rev; 3: 150.

226. Kutnowski M, Vandendris M, Steinberger R, Kraytman M (1977) Prevention of postoperative deep vein thrombosis by low dose heparin in urological surgery. A double blind, randomized study. Urol Res; 5: 123.

227. Sebeseri O, Kummer H, Zingg E (1975) Controlled prevention of post-operative thrombosis in urological disease with depot heparin. Eur Urol; I: 229.

228. Bigg SW, Catalona WJ (1992) Prophylactic mini-dose heparin patients undergoing radical retropubic prostatectomy. Urology; 39: 309-313.

229. Vandendris M, Kutnowski M, Futeral B, Giankopoulos X, Kraytman M, Gregoir W (1980) Prevention of postoperative deep vein thrombosis by low dose heparin in open prostatectomy. Urol Res; 8: 219.

230. Collins R, Scrimgeour A, Yusuf S, Peto R (1988) Reduction in fatal pulmonary embolism and venous thrombosis by perioperative administration of subcutaneous heparin. Overview of results of randomized trials in general, orthopedic and urologic surgery. New Engl J Med; 318: 1162.

231. Le Gagneux F, Steg A, Le Guillou M (1987) imag Subcutaneous enoxaparine (Lovenox) versus placebo for preventing deep vein thrombosis (DVT) after transurethral prostatectomy (TUP). Thromb Haemost; 58: 116.

232. Sawczuk IS, Williams D, Chang DT (2002) Low molecular weight heparin for venous thromboembolism prophylaxis in urologic oncologic surgery. Cancer Invest; 20: 889-892.

233. Koch MO, Smith JA Jr (1997) Low molecular weight heparin and radical prostatectomy: a prospective analysis of safety and side effects. Prostate Cancer Prost Dis; I: 101-104.

234. Koonce J, Selikowitz S, McDougal WS (1986) Complications of low-dose heparin prophylaxis following pelvic lymphadenectomy. Urology; 28: 2I-25.

235. Tomic R, Granfors T, Sjödin JG, Ohberg L (1994) Lymph leakage after staging pelvic lymphadenectomy for prostatic carcinoma with and without heparin prophylaxis. Scand J Urol Nephrol; 28: 273-275.

236. Musch M, Klevecka V, Roggenbuck U, Kroepfl D (2008) Complications of pelvic lymphadenectomy in I,380 patients undergoing radical retropubic prostatectomy between 1993 and 2006. J Urol; 179: 923-928.

237. Khoder WY, Trottmann M, Buchner A et al (20I I) Risk factors for pelvic lymphoceles post-radical prostatectomy. Int J Urol; 18: 638-643.

238. Sieber PR, Rommel FM, Agusta VE et al (1997) Is heparin contraindicated in pelvic lymphadenectomy and radical prostatectomy? J Urol; I58: 869-87I.

239. Nakamura K, Kasraeian A, Yacoub S, Pendleton J, Anai S, Rosser C] (2007) The use of enoxaparin to prevent venous thromboembolism in patients undergoing radic al retropubic prostatectomy: feasibility and utility. Int Braz J Urol; 33: 347-352.

240. Grasso M, Confalonieri S, Blanco S, Grasso A, Angelo S (2009) Preoperative blood donation program and postoperative low molecular weight heparine (LMWH) prophylaxis in patients undergoing radical prostatectomy. Arch Esp Urol; 62: 161-166.

24I. Donat R, Mancey-Jones B (2002) Incidence of thromboembolism after transurethral resection of the prostate (TURP) a study on TED stocking prophylaxis and literature review. Scand J Urol Nephrol; 36: I19-123.

242. Scarpa RM, Carrieri G, Gussoni G et al (2007) Clinically overt venous thromboembolism after urologic cancer surgery: results from the @RISTOS Study. Eur Urol; 5I: 130-135.

243. Cerruto MA, D'Elia C, Piccoli M et al (2016) Association between postoperative thromboembolism prophylaxis and complications following urological surgery. Exp Ther Med; I I: 157-163.

244. Coe NP, Collins RE, Klein LA et al (1978) Prevention of deep vein thrombosis in urological patients: a controlled, randomized trial of low-dose heparin and external pneumatic compression boots. Surgery; 83: 230-234.

245. Koya MP, Manoharan M, Kim SS et al (2005) Venous thromboembolism in radical prostatectomy: is heparinoid prophylaxis warranted? BJU Int; 96: 1019-1021.

246. Cisek L, Walsh P (1993) Thromboembolic complications following radical retropubic prostatectomy. Influence of external sequential compression devices. Urology; 42: 406-408.

247. Cindolo L, Salzano L, Mirone V et al (2009) Thromboprophylaxis in radical retropubic prostatectomy: efficacy and patient compliance of a dual modality. Urol Int; 83: 12-18.

248. Coe W, Collins REC, Klein LA et al (1978) Prevention of deep vein thrombosis in urological patients: controlled randomized trial of low dose heparyn and external pneumatic compression boots. Surgery; 83: 230.

249. Hansberry KL, Thompson IMJr, Bauman J, Deppe S, Rodriguez FR (1991) A prospective comparison of thromboembolic stocking, external Sequential pneumatic compresssion stocking and heparin sodium/dihydroerotamine mesylate for the prevention of thromboembolic complications in urological surgery. J Urol; 145: 1205-1208.

250. Montgomery JS, Wolf JS (2005) Venous thrombosis prophylaxis for urological laparoscopy: fractionated heparin versus sequential compression device. J Urol; 173: 1623-1626.

25I. Alberts BD, Woldu SL, Weinberg AC, Danzig MR, Korets R, Badani KK (2014) Venous thromboembolism after major urologic oncology surgery: a focus on the incidence and timing of thromboembolic events after 27,455 operations. Urology; 84 : 799-806.

252. VanDlac AA, Cowan NG, Chen $Y$ et al (2014) Timing, incidence and risk factors for venous thromboembolism in patients undergoing radical cystectomy for malignancy: a case for extended duration pharmacological prophylaxis. J Urol; 191: 943-947.

253. Kukreja JE, Levey HR, Scosyrev E et al (2015) Effectiveness and safety of extended-duration prophylaxis for venous thromboembolism in major urologic oncology surgery. Urol Oncol; 33: 387.

254. Kahn SR, Lim W, Dunn AS et al (2012) Prevention of VTE in nonsurgical patients: Antithrombotic Therapy and Prevention of Thrombosis, 9th ed: American College of Chest Physicians Evidence-Based Clinical Practice Guidelines. Chest; I4 I (2 Suppl): el 95S-226S. 
255. Samama MM, Cohen AT, Darmon JY et al (1999) A comparison of enoxaparin with placebo for the prevention of venous thromboembolism in acutely illmedical patients. N Engl J Med; 34I: 793-800.

256. Leizorovicz A, Cohen AT, Turpie AG et al (2004) Randomized, placebo-controlled trial of dalteparin for the prevention of venous thromboembolism in acutely ill medical patients Circulation; I 10: 874-879.

257. Cohen AT, Davidson BL, Gallus AS et al (2006) Efficacy and safety of fondaparinux for the prevention of venous thromboembolism in older acute medical patients: randomized, placebo controlled trial. BMJ; 332: 325-329.

258. Bergmann JF, Neuhart E (1996) A multicenter randomized double-blind study of enoxaparin compared with unfractionated heparin in the prevention of venous thromboembolic disease in elderly in-patients bedridden for an acute medical illness. Thromb Haemost; 76: 529-534.

259. Harenberg J, Roebruck P, Heene DL (1996) Subcutaneous low-molecularweight heparin versus standard heparin and the prevention of thromboembolism in medical inpatients. Haemostasis; 26: 127-139.

260. Lechler E, Schramm W, Flosbach CW (1996) The venous thrombotic risk in non-surgical patients: epidemiological data and efficacy/safety profile of a low-molecular-weight heparin (enoxaparin). The PRIME Study Group. Haemostasis; 26 (suppl 2): 49-56.

26I. Kleber FX, Witt C, Vogel G et al (2003) Randomized comparison of enoxaparin with unfractionated heparin for the prevention of venous thromboembolism in medical patients with heart failure or severe respiratory disease. Am Heart J; 145: 614-621.

262. Schellong SM, Haas S, Greinacher A et al (2010) An open-label comparison of the efficacy and safety of certoparin versus unfractionated heparin for the prevention of thromboembolic complications in acutely ill medical patients: CERTAIN. Expert Opin Pharmacother; II: 2953-296I.

263. Riess $\mathrm{H}$, Haas $\mathrm{S}$, Tebbe $U$ et al (2010) A randomized, double-blind study of certoparin vs. unfractionated heparin to prevent venous thromboembolic events in acutely ill, non-surgical patients: CERTIFY Study. J Thromb Haemost; 8: 1209-1215.

264. Akl, EA, Vasireddi SR, Gunukula S et al (20II) Anticoagulation for patients with cancer and central venous catheters. Cochrane Database Syst Rev; CD006468.

265. Goldhaber SZ (2010) Risk factors for venous thromboembolism. J Am Coll Cardiol; 56: I-7.

266. Timp JF, Braekkan SK, Versteeg HH et al (20I3) Epidemiology of cancer-associated venous thrombosis. Blood; 122: 17/2-1723.

267. Walker AJ, West J, Card TR, Humes DJ, Grainge MJ (2014) Variation in the risk of venous thromboembolism in people with colorectal cancer: a population-based cohort study from England. J Thromb Haemost; 12: 64I-649.

268. Streiff MB (2013) Association between cancer types, cancer treatments, and venous thromboembolism in medical oncology patients. Clin Adv Hematol Oncol; I I: 349-357.

269. Sood S (2009) Cancer-associated thrombosis. Curr Opin Hematol; 16: 378-385.

270. Roselli M, Ferroni P, Riondino S et al (2013) Impact of chemotherapy on activated protein $\mathrm{C}$-dependent thrombin generation - association with VTE occurrence. Int J Cancer; 133: | 253-| 258.

27I. Falanga A, Marchetti M (2012) Anticancer treatment and thrombosis. Thromb Res; 129: 353-359.
272. Deitcher SR, Gomes MP (2004) The risk of venous thromboembolic disease associated with adjuvant hormone therapy for breast carcinoma: a systematic review. Cancer; 101: 439-449.

273. Perry JR (2010) Anticoagulation of malignant glioma patients in the era of novel antiangiogenic agents. Curr Opin Neurol; 23: 592-596.

274. Khorana AA, Kuderer NM, Culakova E et al (2008) Development and validation of a predictive model for chemotherapy-associated thrombosis. Blood; I I : 4902-4907.

275. Ay C, Dunkler D, Simanek R et al (2010) Prediction of venous thromboembolismin cancer patients. Blood; I 16: 5377-5382.

276. Ben-Aharon I, Stemmer SM, Leibovici L, Shpilberg O, Sulkes A, Gafter-Gvili A (2014) Low molecular weight heparin (LMWH) for primary thrombo-prophylaxis in patients with solid malignancies - systematic review and meta-analysis. Acta Oncol; 53: 1230-1237.

277. Agnelli G, Gussoni G, Bianchini C ET al (2009) Nadroparin for the prevention of thromboembolic events in ambulatory patients with metastatic or locally advanced solid cancer receiving chemotherapy: a randomised, placebo-controlled, double-blind study. Lancet Oncol; 10: 943-949.

278. Zangari M, Barlogie B, Anaissie E et al (2004) Deep vein thrombosis in patients with multiple myeloma treated with thalidomide and chemotherapy: effects of prophylactic and therapeutic anticoagulation. Br J Haematol; |26: 7| 5-72।.

279. De Stefano V, Za T, Rossi E (2014) Venous thromboembolism in multiple myeloma.Semin Thromb Hemost; 40: 338-347.

280. Palumbo A, Cavo M, Bringhen $S$ et al (20II) Aspirin, warfarin, or enoxaparin thromboprophylaxis in patients with multiple myeloma treated with thalidomide: a phase III, open-label, randomized trial. J Clin Oncol; 10: 29.

28I. Hicks LK, Haynes AE, Reece DE et al (2008) A meta-analysis and systematic review of thalidomide for patients with previously untreated multiple myeloma. Cancer Treat Rev; 34: $442-452$.

282. Maraveyas A, Waters J, Roy R et al (2012) Gemcitabine versus gemcitabine plus dalteparin thromboprophylaxis in pancreatic cancer. Eur J Cancer; 48: I283-1292.

283. Haas SK, Freund M, Heigener D et al (2012) Low-molecular-weight heparin versus placebo for the prevention of venous thromboembolism in metastatic breast cancer or stage III/IV lung cancer. Clin Appl Thromb Hemost; 18: 159-165.

284. Agnelli G, Gussoni G, Bianchini C et al (2009) Nadroparin for the prevention of thromboembolic events in ambulatory patients with metastatic or locally advanced solid cancer receiving chemotherapy: a randomised, placebo-controlled, double-blind study. Lancet Oncol; 10: 943-949.

285. Perry JR, Julian JA, Laperriere NJ et al (2010) PRODIGE: a randomized placebo-controlled trial of dalteparin low-molecular-weight heparin thromboprophylaxis in patients with newly diagnosed malignant glioma. J Thromb Haemost; 8: 1959-1965.

286. Verso M, Gussoni G, Agnelli G (2010) Prevention of venous thromboembolism in patients with advanced lung cancer receiving chemotherapy: a combined analysis of the PROTECHT and TOPIC-2 studies. J Thromb Haemost; 8: 1649-165I.

287. Riess H, Pelzer U, Opitz B et al (2010) A prospective, randomized trial of simultaneous pancreatic cancer treatment with enoxaparin and chemotherapy: Final results of the CONKO-004 trial. J Clin Oncol; 28: 15.

288. Di Nisio M, Porreca E, Otten HM, Rutjes AW (2014) Primary prophylaxis for venous thromboembolism in ambulatory cancer patients receiving chemotherapy. Cochrane Database Syst Rev; 8: CD008500. 
289. Che DH, Cao JY, Shang LH, Man YC, Yu Y (2013) The efficacy and safety of low-molecular-weight heparin use for cancer treatment: a meta-analysis. Eur J Intern Med; 24: 433-439.

290. AkI EA, Kahale LA, Ballout RA et al (2014) Parenteral anticoagulation in ambulatory patients with cancer. Cochrane Database Syst Rev; I2: CD006652.
29I. Hull RD, Schellong SM, Tapson VF et al (2010) EXCLAIM (Extended Prophylaxis for Venous ThromboEmbolism in Acutely III Medical Patients With Prolonged Immobilization) study. Extended-duration venous thromboembolism prophylaxis in acutely ill medical patients with recently reduced mobility: a randomized trial. Ann Intern Med; I53: 8-18. 